\title{
Conditionally Fitted Sharpe Performance with an Application to Hedge Fund Rating
}

\author{
Serge Darolles, Christian Gouriéroux ${ }^{\dagger}$
}

15th June 2009

\begin{abstract}
We define a battery of Sharpe performance measures, which differ by the information taken into account in their computation, but also by the potential use of the fund by the investor. Four advantages of Sharpe performance based rating are especially important for the investor. First, the performance measures correspond to the standard ones used for mutual funds and known by retail investors. Second, the numerical results can be compared, even if they are obtained with different assumptions. Third, the rankings are based on regression analysis and easy to compute. Fourth, these performance measures can be easily used in the design of an optimal basket of hedge funds. Finally, the performance measures are used to partition the set of funds into homogenous segments.
\end{abstract}

JEL Classification: G11.

Keywords: Hedge Fund, Sharpe Ratio, Fitted Performance, Fund Rating, Segmentation.

\footnotetext{
*SGAM Alternative Investments and CREST.

${ }^{\dagger}$ University of Toronto, CEPREMAP and CREST. The authors gratefully acknowledge financial support of the chair Groupama/Risk Foundation: "Behavioral Finance".
} 


\section{Introduction}

The hedge fund industry has grown quickly during the last ten years and represents now about $\$ 1600$ billions of assets and more than 9000 funds. However, this market is still in its infancy, which explains the relative lack of information on the definition of strategies, portfolio allocations, risk and performance measures. As in the mutual fund industry ${ }^{1}$, the current trend is to diffuse information on hedge funds by means of ratings regularly elaborated by specialized agencies and published in general or specialized newspapers. Two kinds of ratings have been historically proposed. The first ones, introduced by Standard and Poor's in the mid-1970s, are qualitative and based on advanced funds due diligence and manager interviews. Due to the cost of such analysis, the results were not free of charge, and only a few funds were analysed. This explains the success of quantitative ratings based on historical return data, first proposed by Morningstar in the mid-1980s, then followed by Standard and Poor's, Lipper, Aptimum and more recently by Europerformance-Edhec [see e.g. Amenc, Le Sourd (2005) for a detailed study of these ratings]. These ratings can easily be proposed free of charge; they already cover all mutual funds and can be successfully adapted to hedge funds, at least in a preliminary analysis. Indeed, most hedge funds use highly dynamic investment strategies, can have short sell and, in this respect, are different from mutual funds. But, even if we have full transparency on the holdings at some specific dates, we don't get the whole information on the dynamic strategy followed by the fund manager. Historical return data ${ }^{2}$ are generally the only source of information for performance estimation and risk analysis. Indeed, retail investors do not have access to managed accounts facilities (i.e. full transparency on the fund holdings) and then must only use historical returns in their funds selection process. This explains why standard quantitative ratings are also used for hedge funds, at least in a first step. These quantitative ratings are most of the time poorly explained, and often misunderstood not only by retail investors, but also by more specialized ones including pension funds, corporates and institutional investors. The aim of this paper is to review in detail the ratings based on the Sharpe performance measures and to standardize their use. We insist on the fact that all performance measures must be investor driven, and not model driven.

In Section 2, we recall the derivation of a conditional Sharpe performance measure in the mean-variance management framework. This derivation shows that different Sharpe performances can be constructed for a given fund. They depend on the information of the investor, but also on the type of other investments, that he/she want to complete by buying/selling the fund and of the investment horizon. As a consequence, there exist as many rankings as ways of defining these performances, and these rankings do not necessarily provide identical results. We also reinterpret in terms of Sharpe performance the use of the so-called

\footnotetext{
${ }^{1}$ The gap between mutual funds and hedge funds is diminishing rapidly with the so-called "hedged mutual funds", that are mutual funds mimicking hedge fund strategies, but still regulated by the Securities and Exchange Commission (SEC) [see Agarwal, Boyson, Naik (2007)].

2 and the design of the allocation between investor's account, provision account and management account [see Darolles, Gourieroux (2009)].
} 
alphas in the ranking process. The persistence question is included by considering the term structure of performances. All these rankings are easy to obtain from simple regression models, and the numerical results can be compared since they come from the same theoretical framework. An application to a set of hedge funds is given in Section 3. We determine and compare the rankings associated with different performance measures such as the historical performance, or a performance when the fund is introduced to complete either the market portfolio, or a portfolio of equities containing the medium or large size firms. We also discuss the pattern of the term structure of performances. Section 4 explains how the performance measures can be used to construct segmentations of hedge funds. When the segmentation is based on a single performance measure, each segment includes the funds with performance in a given interval. We discuss the selection of thresholds providing the best constrast between segments while ensuring enough homogeneity within segments. The method is extended to get homogenous clusters based on several Sharpe performance measures. Section 5 discusses some limitations of the Sharpe performance based rankings and proposes directions for future improvements. Some proofs are gathered in appendices.

\section{Sharpe performance}

Let us first recall how the Sharpe performance is related to the mean-variance portfolio management [see. Prigent (2007) for a general presentation], and explain how it can be used to define individual performances. Then, we study the increase in Sharpe performance, when the set of assets is extended.

\subsection{Mean-Variance efficient portfolio}

Let us denote by $a_{0, t}, a_{1, t}, \ldots, a_{n, t}$ the amounts invested at date $t$ in the different assets $i=0,1 \ldots, n$, where 0 denotes the riskfree asset. The value of the portfolio at date $t$ is $w_{t}=a_{0, t}+\ldots+a_{n, t}$, whereas its future value is uncertain, equal to $w_{t+1}=a_{0, t}\left(1+r_{t}\right)+\sum_{i=1}^{n} a_{i, t} p_{i, t+1} / p_{i, t}$, where $r_{t}$ denotes the riskfree rate at horizon 1 and $p_{i, t}$ the unitary price at $t$ of asset $i$. In the mean-variance framework, the retail investor selects the portfolio allocation by solving the following optimization problem:

$$
\max _{a_{0, t}, \ldots, a_{n, t}} E_{t}\left[w_{t+1}\right]-\frac{A}{2} V_{t}\left[w_{t+1}\right], \text { s.t. } \quad \sum_{i=0}^{n} a_{i, t}=w_{t}
$$

where $\mathrm{A}$ is the individual (absolute) risk aversion, and $E_{t}, V_{t}$ denote the expectation and variance, respectively, given the information used by the retail investor at date $t$. The budget constraint can be solved to get the quantity invested in the riskfree asset: $a_{0, t}=w_{t}-\sum_{i=1}^{n} a_{i, t}$. By substitution, we deduce the unconstrained quadratic optimization problem:

$$
\max _{a_{0, t}, \ldots, a_{n, t}} w_{t}\left(1+r_{t}\right)+E_{t}\left[\sum_{i=1}^{n} a_{i, t} y_{i, t+1}\right]-\frac{A}{2} V_{t}\left[\sum_{i=1}^{n} a_{i, t} y_{i, t+1}\right]
$$


where $y_{i, t+1}=\left(p_{i, t+1}-p_{i, t}\right) / p_{i, t}-r_{t}$. The optimal allocation in the risky assets, $a_{t}^{*}=\left(a_{1, t}^{*}, \ldots, a_{n, t}^{*}\right)^{\prime}$, is given by [see e.g. Markowitz (1952), Merton (1972)]:

$$
a_{t}^{*}=\frac{1}{A} \Sigma_{t}^{-1} m_{t}
$$

where $m_{t}\left[\right.$ resp. $\left.\Sigma_{t}\right]$ is the expectation [resp. the variance-covariance matrix] of the vector of excess returns $y_{t+1}=\left(y_{1, t+1}, \ldots, y_{n, t+1}\right)^{\prime}$. Moreover, the optimal value of the objective function is equal to:

$$
\Pi_{t}=w_{t}\left(1+r_{t}\right)+\frac{1}{2 A} m_{t}^{\prime} \Sigma_{t}^{-1} m_{t}
$$

It depends on the initial budget, on the riskfree rate, on the risk aversion coefficient and on the quantity:

$$
S_{t: 1, \ldots, n}=m_{t}^{\prime} \Sigma_{t}^{-1} m_{t}
$$

which summarizes the stochastic properties of the risky returns [Treynor (1965), Sharpe (1966)]. This quantity is called the Sharpe performance of the set of assets $1, \ldots, n$ at date $t$. The Sharpe performance depends on the information used by the investor to compute the means, variances and covariances. It is called historical Sharpe performance when the computation corresponds to the unconditional mean and variance, and conditional (or potential) Sharpe performance [Jobson, Korkie (1982)], otherwise. The historical and conditional Sharpe performances have different interpretations due to the different information sets, even if their computations are similar. Moreover, the historical performance cannot be deduced from the knowledge of the conditional performance in all environments [see Appendix 1]. As noted early by Sharpe (1994), the use of unadjusted historical Sharpe ratios as surrogates for unbiased estimations of conditional ratios "remained subject to serious question".

\subsection{Individual Sharpe performance}

As an illustration, let us consider a portfolio including the riskfree asset and a single risky asset $j$. The associated performance is:

$$
S_{t: j}=m_{j, t}^{2} / \sigma_{j, t}^{2}
$$

The performance can take any positive value. Indeed, even if $m_{j, t}$ is strictly negative, the risky asset is profitable by introducing a negative amount $a_{j, t}$, whenever shortsell is allowed. If the investor has to choose between a portfolio including the riskfree asset and risky asset $j$, and a portfolio including the riskfree asset and risky asset $k$, he/she will prefer the first one if $S_{t: j} \geqslant S_{t: k}$, whenever he/she allocates the assets in a mean-variance efficient way. This explains why competing funds (i.e. asset portfolios) are usually compared and ranked by means of these Sharpe performances $S_{t: j}$. The practitioners generally define the performance as $S_{t: j}^{1 / 2}=\left|m_{j, t}\right| / \sigma_{j, t}$. It corresponds to the so-called Sharpe ratio when expectation 
and volatility are annualized. Of course, $S_{t: j}$ and $S_{t: j}^{1 / 2}$ provide the same ranking. The Sharpe ratio can be interpreted as a "risk premium". Loosely speaking, it represents the change (in \%) of expected return following a $1 \%$ change of the risk $\sigma$ and was originally called reward-to-variability ratio. It can also be computed taking into account the sign of the expected excess return as $S r_{t: j}=m_{j, t} / \sigma_{j, t}$ [see the discussion in McLeod, Van Vuuren (2004)].

In practice, the individual performances are not known and have to be estimated from a sequence of asset excess returns $y_{j, t}, t=1, \ldots, T$, say. The estimates depend on the type of individual performance which is considered.

\section{i) Historical individual performance}

When the mean and variance are unconditional, the Sharpe performance is approximated by its sample counterpart:

$$
\widehat{S}_{j}=\frac{\left(\frac{1}{T} \sum_{t=1}^{T} y_{j, t}\right)^{2}}{\frac{1}{T} \sum_{t=1}^{T}\left(y_{j, t}-\frac{1}{T} \sum_{t=1}^{T} y_{j, t}\right)^{2}} .
$$

This estimator is often called ex-post performance to highlight its computation from past observations.

ii) Conditional individual performance

In the conditional framework, we need the list of observable variables $Z_{t-1}$, say, included in the information set, and we have to explain how they are used by the investor to derive the conditional mean and variance. The explanatory variables have been indexed by $t-1$ instead of $t$ to highlight the fact that they have to be known in advance for prediction purpose. For instance, they can include lagged returns or macroeconomic variables. Let us assume that the conditioning is performed by means of a linear regression. The computation of the estimated performance is done in two steps. We first regress the returns on the explanatory variables:

$$
y_{j, t}=\delta_{j}+Z_{t-1} \gamma_{j}+u_{j, t}
$$

which provides estimated coefficients $\widehat{\delta}_{j}(Z), \widehat{\gamma}_{j}(Z)$ and also an estimate of the residual variance ${ }^{3}$ :

$$
\widehat{\sigma}_{j}^{2}(Z)=\frac{1}{T} \sum_{t=1}^{T} \widehat{u}_{j, t}^{2}(Z)=\frac{1}{T} \sum_{t=1}^{T}\left[y_{j, t}-\widehat{\delta}_{j}(Z)-Z_{t-1} \widehat{\gamma}_{j}(Z)\right]^{2} .
$$

In a second step, the estimated conditional individual performance at date $\mathrm{T}$ is:

$$
\widehat{S}_{T: j}(Z)=\left[\widehat{\delta}_{j}(Z)+Z_{T-1} \widehat{\gamma}_{j}(Z)\right]^{2} / \widehat{\sigma}_{j}^{2}(Z)
$$

which depends on the selected regressors (asset returns as well as economic variables) and on date $T$.

\footnotetext{
${ }^{3}$ Assumed to be independent of the past.
} 


\subsection{Fitted Sharpe performance}

Let us now consider the riskfree asset and two risky assets 1 and $j$, say ${ }^{4}$. The investor can construct an efficient portfolio with the riskfree asset and risky asset 1 ; he/she can also construct an efficient portfolio including the three assets. In the first case, the Sharpe performance is:

$$
S_{T: 1}=m_{1, T}^{2} / \sigma_{1, T}^{2}
$$

and, in the second case, the Sharpe performance becomes:

$$
S_{T: 1, j}=\left(m_{1, T}, m_{j, T}\right)\left(\begin{array}{cc}
\sigma_{1, T}^{2} & \sigma_{1 j, T} \\
\sigma_{1 j, T} & \sigma_{j, T}^{2}
\end{array}\right)^{-1}\left(\begin{array}{c}
m_{1, T} \\
m_{j, T}
\end{array}\right) .
$$

The increase in Sharpe performance due to the inclusion of the new asset $j$ is :

$$
S_{T: j \mid 1}=S_{T: 1, j}-S_{T: 1}
$$

The additive decomposition formula ${ }^{5}$ for the joint performance $S_{T: 1, j}$ accounts for the potential correlation between the basic asset 1 and the fund $j$. This increase is a natural criterion to rank different funds, if they are considered to complete another subset of assets. For instance, the risky asset 1 can be a tracker written on the market portfolio ${ }^{6}$, and the funds compared by means of the individual performance measurements $S_{T: j \mid 1}$, if the investor considers portfolios including the tracker and one fund as risky assets. There exist as many performance increments, called fitted performance [Gourieroux, Jouneau (1999)] as choice of benchmark asset 1 . Since in practice, there exist almost as many benchmark portfolios as investors ${ }^{7}$, the computation should be done separately for each investor. This is the first justification of the terminology "fitted".

Another important application of this concept can be found in the design of an optimal basket of funds. In this case, the risky asset 1 can be a candidate basket of funds. It is then immediately possible to quantify the interest of completing this basket with fund $j$ by a direct computation of the fitted performance measure $S_{T: j \mid 1}$. Since the conditional performance varies in time, the selection of the completing fund has to be regularly updated.

The fitted performance has another expression which is useful for interpretation and estimation purpose.

\footnotetext{
${ }^{4}$ The definition is easily extended to any number of risky assets [see Jobson, Korkie (1982), Gourieroux, Jouneau (1999)].

${ }^{5}$ The additive decomposition formula has to be written on the square for the Sharpe ratio.

${ }^{6}$ The risky asset cannot be the market portfolio itself, since the market portfolio is not directly traded on the market.

${ }^{7}$ For retail investor the benchmark portfolio might include mainly real estate, life insurance or pension plan.
} 
Indeed, it can be checked that [see Appendix 2]:

$$
S_{T: j \mid 1}=\frac{\left(m_{j, T}-\frac{\sigma_{j, 1, T}}{\sigma_{1, T}^{2}} m_{1, T}\right)^{2}}{\sigma_{j, T}^{2}-\frac{\sigma_{j, 1, T}^{2}}{\sigma_{1, T}^{2}}} .
$$

To understand the importance of this expression and its interpretation in terms of regression residuals, we will first consider the case of historical fitted performance.

i) Historical fitted performance

When the means, variances and covariances are computed unconditionally, we have:

$$
S_{j \mid 1}=\frac{\left(m_{j}-\frac{\sigma_{j, 1}}{\sigma_{1}^{2}} m_{1}\right)^{2}}{\sigma_{j}^{2}-\frac{\sigma_{j, 1}^{2}}{\sigma_{1}^{2}}},
$$

which is estimated by it sample counterpart. Let us now interpret the numerator and denominator of the expression above. For this purpose, let us introduce the linear regression of $y_{j, t}$ on $y_{1, t}$ :

$$
y_{j, t}=\alpha_{j}(1)+y_{1, t} \beta_{j}(1)+v_{j, t}(1), \text { say } .
$$

The OLS estimators of the coefficients are $\widehat{\alpha}_{j}(1), \widehat{\beta}_{j}(1)$ and the estimator of the variance of the error term is $\widehat{\eta}_{j}^{2}(1)$. The comparison with (2.15) shows that:

$$
\widehat{S}_{j \mid 1}=\widehat{\alpha}_{j}^{2}(1) / \widehat{\eta}_{j}^{2}(1)
$$

This is the so-called Treynor appraisal ratio, when asset 1 is the market portfolio. The regression (2.16) has the following financial interpretation: if the returns of assets 1 and $j$ were (conditionally) uncorrelated, the joint Sharpe performance $S_{T: 1, j}$ would be equal to the sum of individual performances $S_{T: 1}$ and $S_{T: j}$. When the asset returns are correlated, the aim of the regression is to construct the portfolio in assets 1 and $j$, which is (conditionally) uncorrelated with the benchmark portfolio and allows for additional diversification. The allocation of this portfolio is 1 in asset $j,-\beta_{j}(1)$ in asset 1 , and its return is $\alpha_{j}(1)+v_{j, t}(1)$. The need for a preliminary regression is the second justification for the terminology "fitted".

ii) Conditional fitted performance

If we still consider a linear regression framework and some variables $Z_{t-1}$ in the information set, the regression becomes:

$$
y_{j, t}=\delta_{j}+Z_{t-1} \gamma_{j}+y_{1, t} \beta_{j}+w_{j, t}
$$

with estimators $\widehat{\delta}_{j}(1, Z), \widehat{\gamma}_{j}(1, Z), \widehat{\beta}_{j}(1, Z), \widehat{\eta}_{j}^{2}(1, Z)$, say. The estimated conditionally fitted individual performance is: 


$$
\widehat{S}_{T: j \mid 1}(Z)=\left[\widehat{\delta}_{j}(1, Z)+Z_{T-1} \widehat{\gamma}_{j}(1, Z)\right]^{2} / \widehat{\eta}_{j}^{2}(1, Z)
$$

We get as many rankings as choices of explanatory variables and benchmark portfolios.

To summarize, the unconditional/conditional, fitted/unfitted performance measures are simply Sharpe performances computed on regression residuals. They differ by the set of lagged variables and current returns which are introduced. The lagged regressors are introduced to represent the information, whereas the current returns are included for taking into account the inclusion of the fund in the investor's portfolio. Finally, the use of Sharpe ratios has been criticized in the literature, since the hedge fund returns follow a nonsymmetric (unconditional) distribution [see e.g. Moix, Schmidhuber (2001)]. This critic applies to the historical (i.e. unconditional) performance, but not to either the fitted, or conditional measures. Indeed, the pattern of the distribution of the error term matters, not the pattern of the historical distribution of returns.

\subsection{Errors to be avoided}

The mean-variance approach provides a coherent framework for comparing the interests in different investments. Indeed, the various Sharpe performance measures have similar interpretations, and their values can be compared to see the effect of the information, if the lagged variables are different, or to detect the best potential use of the fund, if the current returns are different.

As noted above, these approaches do not provide a unique ranking, but different ones according to the type of portfolio that the investor wants to consider and to the information used to compute the mean and the variance. Other ranking criteria have been introduced in the mean-variance framework by academics or practitioners [see Section 5], but do not feature the coherency of the Sharpe performance approach.

i) Currency risk

The rankings are derived from returns, generally computed in US dollars and appropriate for investor with US dollars as the money unit. They are not appropriate for investors with Euro as the money unit. If returns are not hedged for currency risk, different rankings depending on the money unit, i.e. US dollars, Euro, Yen, should be published to avoid to the retail investor the correction for currency risk by him/herself, which is not standard. On the contrary, if returns are perfectly hedged ${ }^{8}$ for currency risk, we don't have to consider this point. In this case, the monetary unit used for the computation has to be mentioned explicitely.

ii) Ranking based on the deviation to Security Market Line (SML)

This methodology has been initially suggested by Jensen (1968), (1969) as a measure of abnormal performance, and applied after various corrections in a lot of papers on hedge fund performance [see e.g. Ferson, Schadt (1996), Kat, Miffre (2002), Gupta, Cerrahoglu, Daglioglu (2003), Agarwal, Boyson, Naik

\footnotetext{
${ }^{8}$ This corresponds to the case of funds proposed to investors in several currencies, using a currency hedge.
} 
(2007), and Leland (1999) for nonsymmetric distributions].

Let us first consider an historical individual performance. The regression is: $y_{j, t}=\alpha_{j}+u_{j, t}$, say. The OLS estimator of the coefficient $\alpha_{j}$ is $\widehat{\alpha}_{j}=\widehat{m}_{j}$ and its estimated variance is $(1 / T) \widehat{\sigma}_{j}^{2}$. We deduce that the associated Student is equal to $t_{j}=\sqrt{T} \widehat{m}_{j} / \widehat{\sigma}_{j}$. Thus, $\left|t_{j}\right|=\sqrt{T} S_{j}^{1 / 2}$, and $\left|t_{j}\right|$ and $S_{j}$ provide identical rankings.

Let us now consider an historical individual fitted performance. It is easily checked that the estimated variance of $\widehat{\alpha}_{j}(1)$ is not equal to $\widehat{\eta}_{j}^{2}(1) / T$. They differ by a multiplicative factor, which depends on the regressors, but is independent of the fund of interest [see Appendix 3]. Thus, they have to be corrected to get a performance interpretation, even if they provide identical rankings. In fact, these Students play an important role in the mean-variance theory, since they are the basis for testing the efficiency of the benchmark portfolio 1 , that is, the fact that the additional fund is redundant [see e.g. Treynor, Black (1973), Roll (1978), Ferson et al. (1983), Gibbons, Ross, Shanken (1989), Jobson, Korkie (1989)]. This is a very different question and we can hope that the answer would be negative, otherwise it would be difficult to justify the presence of such funds on the markets. Moreover, if the benchmark portfolio is not efficient, efficient and inefficient funds can be above the SML [see Dybvig, Ross (1985)].

In fact, the use of this student comes likely from a misleading interpretation of the notion of abnormal return. Indeed the intercept measures a discrepancy in the expected return, and this expected return will be abnormal if it is too large compared to the corresponding volatility. This is exactly what is done when computing the conditional Sharpe performance.

iii) Other current regressors

Very often the list of current regressors include different types of variables such as current values of macroeconomic variables or nonlinear transformations of current returns. As seen in the discussion above, the lagged values of any variables can be introduced when they belong to the information set of the retail investor and current value of only portfolio returns to fix the benchmark.

For instance, a nonlinear effect of market return (i.e. tracker return) $y_{m, t}$ cannot be considered by regressing $y_{j, t}$ on $y_{m, t}, y_{m, t}^{2}$ and computing the associated fitted performance. This is the so-called market timing ability introduced by [Treynor, Mazuy (1966), Gupta et al. (2003)] and proposed to practitioners by [Douady (2007)]. This approach is misleading. However, the information effect can be captured by regressing $y_{j, t}$ on $y_{m, t}, y_{m, t-1}, y_{m, t-1}^{2}$ taking into account $y_{m}, y_{m}^{2}$ in the information set and selecting the market portfolio as a benchmark portfolio. A second effect can be captured by regressing $y_{j, t}$ on $y_{m, t}$, $y_{d, t}$ where $y_{m, t}$ is the tracker return and $y_{d, t}$ is the return of the at-the-money option written on the market index. Then the benchmark assets are the tracker and the at-the-money option. It can also be captured by regressing $y_{j, t}$ on $y_{m, t}, y_{d, t}, y_{m, t-1}, y_{m, t-1}^{2}, y_{d, t-1}$, and so on. A similar remark applies when a call payoff $\left(y_{m t}-k\right)^{+}$is included among the regressors [Agarwal, Naik (2004), Diez de los Rios, Garcia (2005)]. 


\section{iv) Differents regressors for different funds}

It has also been proposed to introduce different regressors for the funds considered in the comparison to compute the performances and perform the ranking. More precisely, given two funds, 1 and 2, say, the conditional individual performances are computed as $S_{T: 1}\left(Z_{1}\right)$ and $S_{T: 2}\left(Z_{2}\right)$, respectively, and compared. As mentioned in sections above, the same information set has to be used for the comparison. This means that we have to compute $S_{T: 1}\left(Z_{1}\right)$ and $S_{T: 2}\left(Z_{1}\right)$ to get a first ranking, $S_{T: 1}\left(Z_{2}\right)$ and $S_{T: 2}\left(Z_{2}\right)$ to get a second one, $S_{T: 1}\left(Z_{1}, Z_{2}\right)$ and $S_{T: 2}\left(Z_{1}, Z_{2}\right)$ to get a third one. For instance, fund specific information sets are often introduced in the conditional performances, when univariate ARCH models are estimated separately for the different funds. In this approach the regressors are lagged (squared) returns of fund $j$ only, when the conditional performance of $j$ is considered. This misleading methodology is in particular followed in the ARCH based risk model developped by J.P. Morgan [see Daul (2007)].

A similar remark applies to fund specific benchmark portfolios [see e.g. Amenc, Le Sourd (2005)]. This is the core of the Edhec-Europerformance fund rating methodology. By choosing a benchmark portfolio depending on the announced portfolio management category, the authors introduce a selectivity bias in the ranking comparison of hedge funds.

\section{v) Utility based performance}

It has also been proposed to compare the funds by means of a subjective price, which can be computed by either a utility based method [see e.g. Morningstar (2006)], or by a change of probability [see Chen, Knez (1996)]. To understand the drawback of such approaches, let us consider Gaussian returns and the application of the certainty equivalent principle based on a CARA utility function ${ }^{9} u(w)=-\exp (-A w)$. A utility based price of the future portfolio value $w_{t+1}$ is:

$$
\begin{aligned}
\Pi_{t} & =u^{-1}\left[E_{t} u\left(w_{t+1}\right)\right] \\
& =-\frac{1}{A} \log E_{t}\left[\exp \left(-A w_{t+1}\right)\right] \\
& =-\frac{1}{A} \log \left[\exp \left(-A E_{t} w_{t+1}+\frac{A^{2}}{2} V_{t} w_{t+1}\right)\right] \\
& =E_{t}\left(w_{t+1}\right)-\frac{A}{2} V_{t}\left[w_{t+1}\right] .
\end{aligned}
$$

[by the (conditionally) Gaussian assumption]. When the portfolio in mean-variance efficient, we deduce from (2.3) that the utility based price corrected for the initial budget level is [see (2.7)]:

$$
\Pi_{t} / w_{t}=\left(1+r_{t}\right)+\frac{1}{2 A} \frac{m_{t}^{\prime} \Sigma_{t}^{-1} m_{t}}{w_{t}}
$$

Clearly, the values and ranking differ from the values and ranking associated with the Sharpe performance approach in two respects. First, there is an effect of the size of the portfolio. Second, the risk aversion

\footnotetext{
${ }^{9}$ Morningstar is using power utility functions [see Amenc, Le Sourd (2005)], but the argument is the same.
} 
coefficient $A$ (i.e. the selected utility function) matters. It is preferable to propose performance measures based on market data only, i.e. $m_{t}, \Sigma_{t}$ without introducing an ad-hoc risk aversion parameter, which does not necessarily represent the retail investor's preferences. To summarize, the Sharpe performance is an objective indicator, whereas a price computed from the utility function or an ad-hoc change of probability is a subjective indicator.

vi) Performance deduced from average ranks

Finally, another frequent practice is the following. A good fund is basically a fund with high mean returns, low volatility, low correlation with market returns (diversification effect) and positive autocorrelation (persistence effect). A naive way to get a unique ranking including all these features consists in first determining the rankings based on the mean, on the standard deviation, on the correlation with market return, ....., respectively, then averaging these rankings [see the Edhec Europerformance methodology in Amenc, Le Sourd (2005)] to define a "performance" measure. Of course, the definition of this final ranking remains ad hoc, and clearly depends on the weights used when averaging. The numerical results are just average of rankings, without any financial interpretation.

Moreover, whereas the Sharpe performance can be computed separately per fund, the approach based on average ranks requires the determination of the basic ranks, and then an analysis of all funds together, which is much more time consuming. Last, but not least, this approach is highly sensitive to the population of funds which is considered.

\section{Application to Hedge Funds}

In this section we derive and compare the rankings of hedge funds according to a set of conditionally fitted Sharpe performance measures, computed with US $\$$ as the money unit. In the first subsection, we describe the hedge funds database and provide summary statistics on hedge funds returns. In the two following subsections, we select some special funds from different categories and compare their performances.

The conditionally fitted Sharpe performance is clearly appropriate to study hedge fund returns, at least for two reasons. First, hedge fund returns exhibit significant autocorrelations. This dynamic behavior can be related to the illiquidity properties of some investment vehicules used by hedge funds [see Getmansky, Lo, Makarov (2004)], and are specific to these funds since mutual funds do not exhibit the same dynamic behavior. Second, hedge funds are most of the time used by investors to complete an existing portfolio. The fitted characteristic of the proposed performance measure allows to take into account this dimension [see Kat, Palaro (2005), (2007) for the use of investors portfolio in the replication of hedge fund returns distribution and performance measure]. 


\subsection{Summary statistics}

Historical returns are the main source of information for the majority of hedge funds. In addition to historical returns, hedge funds can also be self-declared in one or several categories (called types) from a given list. The Hedge Fund Research (HFR) database includes monthly returns of 5726 hedge funds along with their self-selected categories. We select hedge funds with 36 months of historical returns for the period July 2004-June 2007 and we delete HFR indices. The remaining database includes 2294 single hedge funds and 1100 funds of funds, for which the return data are available on the period of interest. All returns are computed in US dollars. They correspond to a total value of $\$ 901$ billions for both types of funds and $\$ 587$ billions for only the single hedge funds.

[Insert Table 1: The funds by strategy]

We select randomly 36 single hedge funds in different categories and report information on the management company, the self-declared strategy ${ }^{10}$ and the assets under management (see Table 1). We only select single hedge funds and do not consider funds of funds. Indeed, it might be more profitable for a skilled retail investor to manage a portfolio of single funds by himself, in order to avoid the additional fees corresponding to the payment of the fund of funds manager. We introduce the notion of ticker to shortly name each fund in the sample. It is not surprising to find 14 hedge funds in the Equity Long/Short categories (i.e. Equity Hedge, Equity Market Neutral, Equity Non-Hedge and Short Selling). Indeed, this is the most common investment strategy used by hedge fund managers. It consists in buying and selling short equities to generate returns without a full exposure to equity market risk (or with zero exposure in the case of the market neutral substrategy). The categories Macro and Managed Futures correspond to directional strategies on global or specific markets. Relative Value Arbitrage, Convertible Arbitrage, Merger Arbitrage, Event-Driven, Fixed Income Arbitrage and Distressed Securities are relative value strategies, consisting essentially on bets made on abnormal valorisation spreads.

[Insert Table 2: Summary Statistics]

Table 2 provides different summary statistics for the selected hedge funds returns. We compute annualized mean excess return, annualized volatility, current betas and lagged gammas with equity and bond markets ${ }^{11}$. More precisely, the regressions include a single explanatory variable that is either the current value of the benchmark return to capture the fitted aspect, or its lagged value to capture the information effect. The corresponding regression coefficients are called current beta and lagged gamma, respectively. The sample exhibits a high degree of heterogeneity concerning annualized mean excess return and volatility. Even for a same strategy such as Equity Hedge, some funds feature low mean return and volatility (GU EH is in this case) and others feature high return and risk (SP EH is a good example).

\footnotetext{
${ }^{10}$ See Das (2003) for a comparison of the different classifications, i.e. ZCM, HFR, TASS and VanHedge classifications.

${ }^{11}$ We use the SP500 index (resp. the Lehmann US Aggregate Bond index) as a proxy of the equity (resp. bond) market.
} 
The leverage effect is the first explanation. The Sharpe performance, which is a mean by volatility ratio, erases this leverage dimension.

The next comment concerns the high level of computed current betas. If, in theory, hedge funds follow investment strategies producing returns uncorrelated with market returns, we often observe in practice a high positive correlation between hedge fund and market benchmark returns. The case of the two Equity market neutral funds of our sample is interesting. The first one FS EM is effectively market neutral (the FS EM beta on SP500 is around 2\%), but the second one I EM is clearly exposed to Equity risk with a SP500 beta very closed to $100 \%$.

The last comment concerns the lagged gammas. It is surprising to see that some gammas are significantly negative. Indeed, we might expect a zero correlation between returns observed on two different periods. This is clearly not the case when these statistics are computed on individual hedge funds returns. The liquidity issues and the difficulty to compute the mark-to-market of a complex portfolio can explain this feature. This will induce predictability in hedge fund returns and give another argument to compute conditional performances instead of unconditional ones.

\subsection{Comparison of unfitted performances}

In this section and the following one, the theoretical framework of Section 2 is used to construct several rankings from the statistics computed on each fund. Let us first consider an investor with no completing holdings. For each fund, we compute the estimated individual Sharpe performance $\hat{S}_{j}$, the estimated conditional Sharpe performances $\hat{S}_{T: j}(Z)$ using different information sets $Z$. To be in line with industry practices, we report annualized Sharpe ratios instead of individual Sharpe performances. Even if the ranking associated with Sharpe ratio $S_{j}^{1 / 2}$ and Sharpe performance $S_{j}$ are identical, the additive property of fitted performances applies to Sharpe performances, not to Sharpe ratios.

[Insert Table 3: Conditional Sharpe Performance with S\&P Benchmark Portfolio]

Tables 3 and 4 give a first illustration of the impact of information on rankings with lagged regressors based on SP500 and Lehman Bond Index, respectively. If we only use a static Sharpe performance, the ranking depends only on historical mean excess return and volatility. The corresponding results are provided in columns 2 and 3 of Tables 3 and 4 . The most performant fund is FS EM, with a Sharpe ratio equal to 2.57. When lagged SP500 returns are included in the definition of the conditional Sharpe performance, we use observed past return of this equity market benchmark to rank funds. We distinguish two different regimes in Table 3 according if the SP500 is up 1\% or the SP500 is down 1\%. In both cases, FS EM remains the most performant hedge fund, but with a higher performance ratio in down market than in up market. We can also discuss the case of RCG DS. It is a medium fund if we consider its individual performance (Sharpe ratio of 1.49 - rank 13). But the performance of this fund depends a lot on past observed returns. In an up market, the fund is better (Sharpe ratio of $1.67-\operatorname{rank} 7$ ) and less 
performant in down market (Sharpe ratio of 0.85 - rank 30). On the contrary RO ED performs well on down market (Sharpe ratio of 2.41 - rank 4) and is less performant in up market (Sharpe ratio of 1.37 - rank 15). Finally, using conditional performance is in some sense a way to integrate the gamma coefficient in the performance computation. The funds with stable performance accross equity environment correspond to low gamma parameters. The fund FS EM is a good example in this respect.

[Insert Table 4: Conditional Sharpe Performance with Lehman US Agg Benchmark Portfolio]

The same type of comments can be made on Table 4, which takes into account the influence of past bond market performance. RC EH and DF MH are the two funds with high gamma parameter. DF MF is globally not the most performant (Sharpe ratio of 1.67 - rank 8), but its performance in down market is exceptional (Sharpe ratio of 2.51 - 1st rank) and poor in up market(Sharpe ratio of 1.02 - rank 29).

\subsection{Comparison of fitted performances}

Let us still consider the same 36 funds studied as before, and an investor with initial holdings. The initial holdings are either a portfolio fully invested in US Equity, denoted $P=E$ (the portfolio return is then equal to SP500 return), or a portfolio fully invested in US Bonds, denoted $P=B$ (the portfolio return is equal to Lehmann Bonds index return). These two portfolios can be interpret as proxies of the usual investment strategies followed by retail investors. For example, for life insurance products, three risk profiles are often defined: dynamic, diversified and defensive. The Equity [resp. Bond] portfolio can be associated with the dynamic [resp. defensive] profile and the diversified one corresponds to an equally weighted allocation beetween the Equity and Bond portfolios ${ }^{12}$. We compute estimated fitted Sharpe performance $\hat{S}_{j \mid P}$ and estimated conditionally fitted Sharpe performance $\hat{S}_{T: j \mid P}$ for each of these initial holdings $P=E$ or $B$.

[Insert Table 5: Fitted Performance and Ranking with S\&P Benchmark Portfolio]

Table 5 provides ranking of the set of hedge funds when the initial holding $P$ is the Equity portfolio. The left part of the Table (Fitted performance) can be first compared to the column providing the historical performance. If FS EM is still among the most performant funds, other funds have their rank significantly modified. For example, LES SS inproves its ranking due to its negative beta $(-151 \%)$ with the equity market. This characteristics is intrinsic to the strategy - short selling, and ensures a good protection for equity investors ${ }^{13}$. More generally, funds with low absolute beta w.r.t. equity markets improve their ranking. On the contrary, I EM, announced as equity market neutral, features a surprising high equity beta, and is ranked 15 instead of 6 regarding historical performance only. Finally, due to the

\footnotetext{
${ }^{12}$ We miss in this setup the real estate exposure met in most of retail investor portfolios (which is left for future research) and only consider liquid investments.

${ }^{13}$ This ranking is obtained with a negative associated alpha. The hedging effect associated with this fund is so good that the investor accepts to pay a premium to buy it.
} 
decomposition formula (2.12), the fitted performances are always lower than the individual performances. To summarize S\&P500 and Lehmann US Agg are market factors with instantaneous effect on the hedge fund returns. These effects are strongly dependent of the fund [see also Schneeweis, Kazemi, Gupta, Daglioglu (2003)]. They have to be accounted for, according to the need of the investors.

The lagged values of market factors can also be considered in the information set. The right part of Table 5 concerns conditionally fitted performance and reports the ranking when lagged and diversification effects are both included. We only consider one regime: past SP500 return is up 1\%. FS EM is no longer the most performant fund and LES SS is now the fund ranked $n^{\circ} 1$. This latter fund takes advantage of its negative beta with $S P 500$ returns and positive correlation with lagged $S P 500$ returns.

[Insert Table 6: Fitted Performance and Ranking with Lehmann US Agg Benchmark Portfolio]

The same type of analysis can be done for investors who complete a portfolio including bonds. Table 6 includes the correlation with bond market in the ranking. As before FS EM benefits from its lack of correlation with the bond market and increases its rating compared to the static case. The other funds do not have their rank significantly modified. On the contrary, if we consider conditionally fitted performances, we recover some changes of ranking.

\subsection{Term Structure of Performance}

Retail investors can differ in their holding horizons often larger than for banks and it is important to analyse how the performance depends on this horizon [see e.g. Levy (1972), (1984), Chen, Lee (1986), Levy, Samuelson (1992), Hodges, Taylor, Yoder (1997)]. The performances depend on the selected investment horizon by means of the definition of the returns and the lag in conditioning variables. By considering a varying horizon, we can construct the term structures of (unconditional/conditional, fitted/unfitted) Sharpe performance (TSSP) and the associated term structures of ranking.

In the simple case of i.i.d. (continuously compounded) returns, the conditional and unconditional perfor-

mances at horizon $h$ coincide and are equal to $S_{j, h}=\frac{h^{2} m_{j}^{2}}{h \sigma_{j}^{2}}=h S_{j}$, since the mean and variance are both multiplied by $h$. Thus, in the i.i.d. framework, we get a linear term structure of performance, a square root pattern of Sharpe ratios and a flat term structure of ranks. The term structure pattern is often very different in practice, due to more complex return dynamic. The recent literature on hedge funds emphasized the importance of persistence in hedge fund returns. While some authors [see e.g. Agarwal, Naik (2000), Edwards, Caglayan (2001)] have found overall evidence of persistence, the results are less clear at the hedge fund level. In fact, the term structure of Sharpe performances provides the complete information on serial dependence of hedge fund returns, which is more appealing than the standard autocorrelogram, for instance. Indeed, let us assume for expository purpose, that the performances are 
computed on excess geometric returns:

$$
y_{j, t+1} \simeq \log \left[p_{j, t+1} /\left(1+r_{t}\right) p_{j, t}\right]
$$

that is, ignore the effect of compounding as in [Lo (2002)]. If the geometric excess returns are second-order stationary, the unconditional Sharpe performance at horizon $h$ is:

$$
\begin{aligned}
S_{j, h} & =\frac{\left[E\left(y_{j, t+1}+\ldots+y_{j, t+h}\right)\right]^{2}}{V\left(y_{j, t+1}+\ldots+y_{j, t+h}\right)} \\
& =\frac{h^{2} E\left(y_{j, t+1}\right)}{h V\left(y_{j, t+1}\right)+2(h-1) \operatorname{cov}\left(y_{j, t+1}, y_{j, t+2}\right)+\ldots+2 \operatorname{cov}\left(y_{j, t+1}, y_{j, t+h}\right)} \\
& =\frac{h S_{j}}{1+2\left(1-\frac{1}{h}\right) \rho(1)+\ldots+2\left(1-\frac{h-1}{h}\right) \rho(h-1)},
\end{aligned}
$$

where $\rho(h)$ denotes the autocorrelation at order $h$ of the geometric returns. Thus, the term structure of Sharpe performances provides the complete information on the serial correlations of return. Since the compounding has been neglected, we cannot really consider:

$$
\lim _{h \rightarrow \infty} \frac{1}{h} S_{j, h}=\frac{S_{j}}{1+2 \sum_{j=1}^{\infty} \rho(h)},
$$

as the long term unconditional Sharpe performance [see Stutzer (2000) and Liu, Chou (2003) for the effect of compounding in the long run]. Note also that the interpretation of the term structure of Sharpe performance in terms of autocorrelation (i.e. Equation (3.1)) is no longer valid for conditional/fitted performances.

[Insert Figure 1: Term Structure of Historical Sharpe Performances]

As an illustration, we provide in Figure 1 the term structure of historical Sharpe performances for seven funds. The term structures feature various patterns. They can be increasing, or decreasing, convex or concave, possibly with bumps. We also observe crossing of the term structures of Sharpe ratios, which will imply non flat term structures of rating and very different rankings for short and long term investors. The term structure of Sharpe performance can provide information on the strategy of the fund, especially on the part of its allocation which is illiquid and on the restricted investments.

If the fund FS EM is ranked number 1 at all horizons ${ }^{14}$, some others funds can suffer when the horizon considered in the ranking procedure increases. It is in particular true for SP EH, third fund at horizon 1 , but worst fund when the horizon is higher than 4 . This is due to a higher volatility estimate when we use multiperiod returns in the estimation procedure. The i.i.d. assumption is in this case clearly broken, and autocorrelation between returns can explain this result. Smoothing techniques applied on returns or liquidity effects can be the causes of such phenomenon [see e.g. Getmansky and al. (2004)]. Considering

\footnotetext{
${ }^{14}$ This is not surprising since FS EM was a feeder fund for Madoff.
} 
the whole term structure of performances is then a solution to avoid performance manipulation (in the case of smoothing).

[Insert Figure 2: Term Structure of Fitted Sharpe Performances]

Figure 2 provides the same results, but based on the Fitted (with SP500) Sharpe performances. For most of the funds in the sample, we do not observe the expected increasing pattern of the performance term structure. The joint behavior of FS EM and LES SS can be commented. In the short term (1 to 4 months), the two funds are close in terms of performance. For medium term (around 6 months), LES SS is the best performing fund for an Equity investor, but in the long term (1 year), FS EM is the first choice. This example shows that the investment horizon is a key parameter in any ranking procedure.

\section{Segmentation}

The conditional fitted performance measures are summary statistics, which can be used to construct homogenous segments of hedge funds. These segments can be based on one or several performance measures. Using cluster analysis to get homogenous segments of hedge funds has already been proposed by Das (2003) and Gibson and Gyger (2007). A recent study by BNY Mellon (2007) emphasizes the importance of controlling the hedge funds strategies self-declared by the managers and currently used by the industry without any validation by the regulator.

\subsection{The principle}

\subsubsection{Segmentation based on a single performance measure}

Let us choose a given type of performance measure, such as the unconditional unfitted performance measure $S_{j}, j=1, \ldots, N$. Then, $K$ segments, denoted $A_{k}, k=1, \ldots, K$, can be defined by introducing classes of performance values. Segment $A_{k}$ includes the funds such that:

$$
a_{k-1}<S_{j}<a_{k}
$$

where $a_{0}=0<a_{1} \ldots<a_{K+1}=\infty$ are given thresholds. For a fixed number $K$ of classes, these thresholds can be selected to get the best contrast between segments. Let us denote by $\overline{S_{k}}$ the average performance of the $N_{k}$ funds belonging to class $k$ and $\bar{S}$ the average performance computed on the whole population. The total variance can be decomposed as the sum of the between and within variances ${ }^{15}$ :

$$
\frac{1}{N} \sum_{j=1}^{N}\left(S_{j}-\bar{S}\right)^{2}=\frac{1}{N} \sum_{k=1}^{K} \sum_{j \in A_{k}}\left(S_{j}-\bar{S}_{k}\right)^{2}+\frac{1}{N} \sum_{k=1}^{K} N_{k}\left(\bar{S}_{k}-\bar{S}\right)^{2}
$$

\footnotetext{
${ }^{15}$ In the variance decomposition formula, the different hedge funds are equiweighted. Alternative decompositions could account for either the size of the hedge funds, or the accuracy of the estimated performance measures.
} 
An optimal segmentation is derived by looking for segments which are as homogenous as possible. It is obtained by minimizing the within component (or equivalently by maximizing the between component). The clustering solution of the optimisation problem is easily derived by following a recursive approach, which explains how to merge two intermediate segments while increasing the criterion value. This procedure starts with the $N$ segments including only one hedge fund, then merges the two closest hedge funds and so on. It is known that this optimal approach provides segments corresponding to intervals of performance values, or equivalently to an optimal partition $a_{0}=0<a_{1} \ldots<a_{K+1}=\infty$. The standard procedures (and softwares) propose also methodologies for selecting an "optimal" number $K$ of classes, based on the analysis of the ratio between the within and total variances. Since hedge fund performances can be seen as rating of hedge fund managers, it seems preferable to follow the standard practice suggested by the regulators for risk and to impose a standardized number of classes, between 8 and 10. These classes will be the analogues of the standard AAA, AA,...

The approach above can also be extended to conditional performance measures. Since these measures depend on time by means of the environment, it is important to distinguish between environment dependent and environment independent clustering. More precisely, we can consider an environment dependent variance decomposition formula:

$$
\frac{1}{N} \sum_{j=1}^{N}\left(S_{j t}-\bar{S}_{t}\right)^{2}=\frac{1}{N} \sum_{k=1}^{K} \sum_{j \in A_{k t}}\left(S_{j t}-\bar{S}_{k t}\right)^{2}+\frac{1}{N} \sum_{k=1}^{K} N_{k t}\left(\bar{S}_{k t}-\bar{S}_{t}\right)^{2}
$$

and apply optimal clustering to get environment dependent partition $a_{0, t}<a_{1, t} \ldots<a_{K+1, t}$, for any $t$. Alternatively, we can look for an environment independent variance decomposition formula:

$$
\frac{1}{N T} \sum_{t=1}^{T} \sum_{j=1}^{N}\left(S_{j t}-\bar{S}\right)^{2}=\frac{1}{N T} \sum_{t=1}^{T} \sum_{k=1}^{K} \sum_{j \in A_{k}}\left(S_{j t}-\bar{S}_{k}\right)^{2}+\frac{1}{N T} \sum_{t=1}^{T} \sum_{k=1}^{K} \bar{N}_{k}\left(\bar{S}_{k}-\bar{S}\right)^{2}
$$

where:

$$
\bar{S}=\frac{1}{T} \sum_{t=1}^{T} \bar{S}_{t}, \bar{S}_{k}=\frac{1}{T} \sum_{t=1}^{T} S_{k t}, \bar{N}_{k}=\frac{1}{T} \sum_{t=1}^{T} N_{k t}
$$

and derive an optimal clustering $a_{0}<a_{1} \ldots<a_{K+1}$. The first approach is the most appropriate, since the definition of segments is intuitively not the same for high volatility periods and low volatility periods, or during the expansion and recession phases of the cycle. The standard regulation for risk (Basel 2) proposes in a first step to select environment independent thresholds for the regulatory analysis of risk, but allows a point-in-time (PIT) approach to account for the position within the cycle when using the internal model. A similar strategy might be followed for performance based segmentation.

A similar discussion could be done concerning the self-declared strategies. Indeed, these strategies are currently declared at the issuing of the hedge fund and not regularly updated later on. They are environment independent, and the information on the strategies could have been improved by producing 
environment dependent self-declared strategies. This is especially important when some strategies, such as short selling, are automatically inappropriate in some environment and leading to big losses if really followed. This question is clearly out of the scope of this paper.

To summarize, there exist as many segmentations as underlying Sharpe performance measures and environments. These segmentations have to be considered jointly and compared to the self-declared strategies.

\subsubsection{Segmentation based on several performance measures}

As above optimal homogenous segments can be derived by minimizing the within component is a "variance decomposition equation". The criterion has to involve jointly the different performance measures $S_{l}$, $l=1, \ldots, L$, say. For this purpose, let us introduce an Euclidean norm:

$$
\|S\|^{2}=\left(S_{1}, \ldots, S_{L}\right) \Sigma^{-1}\left(S_{1}, \ldots, S_{L}\right)^{\prime},
$$

where $(.)^{\prime}$ denotes transpose and $\Sigma$ is a symmetric positive definite matrix defining the selected metric. In practice $\Sigma$ is often selected as $\Sigma=I d$, where $I d$ denotes the identity matrix, or as an estimated variance-covariance matrix of the estimated performance to account for the correlation structure between the different ranking criteria. The total inertia can be decomposed into the between and within inertia as:

$$
\frac{1}{N} \sum_{j=1}^{N}\left\|S_{j}-\bar{S}\right\|^{2}=\frac{1}{N} \sum_{k=1}^{K} \sum_{j \in A_{k}}\left\|S_{j}-\bar{S}_{k}\right\|^{2}+\frac{1}{N} \sum_{k=1}^{K} N_{k}\left\|\bar{S}_{k}-\bar{S}\right\|^{2} .
$$

Whereas the optimal segments based on a single performance measure correspond to consecutive intervals and can be ranked without ambiguity, the optimal segments based on several performance measures can have various patterns. The optimal segments are not obtained in general by crossing intervals based on the single performance measures, and cannot be ordered. Performance based classification will generally provide different results than a classification performed on other summary statistics such as return histories [see e.g. Brown, Goetzmann (2003)], or binary attributes [see e.g. Das (2003)].

\subsection{Application to hedge funds}

Let us illustrate the segmentation approaches described in Section 4.1. For this purpose, we consider the set of hedge funds for which the return data are complete. We get 2294 funds and compute five performance measures, that are the historical Sharpe Ratio, the SP500 Fitted Sharpe Ratio, the SP500 conditionally Fitted Sharpe Ratio, the Bond Fitted Sharpe Ratio and the conditionally Bond Fitted Sharpe Ratio. For this illustration, the conditional performances are computed for a fixed return of the conditioning variable (up 1\%) and they are not averaged over time. 


\subsubsection{Segmentation based on a single performance measure}

Let us first consider the unconditional performance measure $S_{j}$.

[Insert Table 7: Inertia Decomposition as Function of the Number of Clusters]

Then, we have applied the automatic segmentation approach described in Section 4.1 for different numbers of clusters. Table 7 gives the associated variance decomposition. The number $K=10$, which is suggested by the regulator for credit risk, seems also appropriate in performance analysis, since the gain in inertia becomes rather small for larger value $K$. We fix $K=10$ in further analysis.

[Insert Table 8: Cluster Description for Historical Sharpe Ratio]

The cluster characteristics are displayed in Table 8 by increasing order of performances. For each cluster, we give the number of funds, the lowest, the highest and the mean performances. The clusters can have rather heterogeneous sizes, but the clusters with small size correspond often to extreme performances. This explains why it is not necessarily useful to merge them with others classes. A similar analysis can be done for the conditionally (fitted) performance measures. We consider the fitted performances with SP500 benchmark, the fitted performances with Bond benchmark, the conditionally fitted performances with SP500 benchmark and the conditionally fitted performances with Bond benchmark.

[Insert Table 9: Cluster Description for Fitted Sharpe Ratios]

[Insert Table 10: Cluster Description for Cond. Fitted Sharpe Ratios]

Tables 9 and 10 display the distribution of funds among the segments of both types, conditional and unconditional. The number of large segments, i.e. including more than 100 funds, is $6,5,6,5,5$, respectively, and they correspond to different limiting thresholds. In particular, the ratings based on two different performances are not comparable, that is, the ranks of the clusters cannot be compared between Table 8 and Table 9 (or 10). For instance, rating 2 (i.e. AA in the standard terminology) corresponds to segments with size $8,2,8,10,2$, respectively, and to intervals [7.8,14.27], [11.9, 14.81], [7.81, 14.70], $[6.69,14.29],[11.58,14.08]$, respectively. Even if the $1^{\text {st }}, 3^{d}, 4^{\text {th }}$ intervals [resp. $2^{\text {nd }}, 5^{\text {th }}$ ] are similar, they apply to performances with highly different interpretation. In other words, we cannot assimilate oranges and bananas, AAA for corporate bonds and AAA for CDO's, or AAA for unfitted and fitted performances.

\subsubsection{Segmentation based on several performance measures}

Finally, we consider a direct segmentation based jointly on $S_{j}$ and the 4 different performances introduced in the previous subsection.

[Insert Table 11: Inertia Decomposition with Cluster Number - All Performance Measures]

[Insert Table 12: Cluster Description Projected on Each Sharpe Ratio] 
Table 11 provides the inertia decomposition related to this case. The clusters are defined in a 5dimensional space of Sharpe ratios and can admit rather complicated patterns. Table 12 provides the projections of the clusters on each 1-dimensional performance direction. We observe that the projected clusters define intervals of performances which generally intersect.

[Insert Table 13: Self-Declared Strategies Comparison]

Table 13 provides the distribution by self-declared strategy ${ }^{16}$ for each cluster. It is difficult from Table 13 to see if the self-declared strategy is informative of the future results, at least when they are measured in terms of Sharpe performance. The existence of several styles with highly different performances show that "the term hedge fund emcompasses investment philosophies that range far from the risk-neutral strategy of (Alfred Winslow) Jones" [Jones (1949), Brown, Goetzmann (2003)]. Moreover, "many investment firms are simply renaming their trading desk as hedge funds". They satisfy the regulatory controls concerning leverage, short-selling, holding shares of other investment companies..., but they have a complete freedom, otherwise, especially for using the self-declared strategies as a marketing tool. This is the strategic selfmisspecification discussed in Brown, Goetzmann (1997) for mutual funds, which can weaken the observed dependence.

To perform a more accurate analysis, we consider a chi-square test for independence. A chi-square test can only be applied if the size of the marginal cells are large enough. For this reason, we consider 7 aggregate clusters $\{1,2,3,4\}, 5,6,7,8,9,10$ and 5 management styles, i.e. Equity Hedge, Equity Market Neutral, Macro, Managed Futures, Fixed Income Arbitrage. Let us denote by $Y_{i, j}$ the number of funds in aggregate cluster $i$ and category $j$. We want to test the null hypothesis of independence:

$$
H_{0}: p_{i, j}=p_{i .} p_{. j}, i=1, \ldots, 7, j=1, \ldots, 5,
$$

where $p_{i, j}$ (resp. $p_{i,}, p_{. j}$ ) denotes the probability of being in aggregate cluster $i$ and aggregate category $j$ (resp. in cluster $i$, in category $j$ ). We then compute the chi-square test statistic:

$$
Q=\sum_{i=1}^{7} \sum_{j=1}^{5} \frac{\left(Y_{i, j}-N \hat{p}_{i . \hat{p}_{. j}}\right]^{2}}{N \hat{p}_{i .} \hat{p}_{. j}}
$$

where $N$ is the total numbers of funds, $\hat{p}_{i .}$ and $\hat{p}_{. j}$ the frequency counterpart of $p_{i}$. and $p_{. j}$, respectively. The terms in the chi-square sum are provided in Table 15.

[Insert Table 14: Decomposition of the Chi-Square Statistic]

Under the null hypothesis, the test statistic $Q$ follows a chi-square distribution with $(7-1)(5-1)=24$ degrees of freedom. We must reject $H_{0}$ at a $5 \%$ level if $Q>36$. We get $Q=364$ and then reject the independence hypothesis. Therefore, the performance of a particular fund depends on the self-declared

\footnotetext{
${ }^{16}$ see Lhabitant (2002) for a description of the main management styles.
} 
strategy. A more detailled analysis can be done by comparing each element of Table 14 with the critical value 3.86 corresponding to a chi-square with 1 degree of freedom. The main reason for the global dependence between style and performance is the high performances of fixed arbitrage funds.

This result supports the top-down approach used in the most common funds of funds allocation process. First, the fund manager defines a strategic allocation between strategies, and then picks funds inside each strategy. If the independence between strategies and performance were not rejected, it would be possible to directly define an optimal allocation in selecting the best performing funds, without any consideration on the strategies. This approach is called bottom-up in the asset management industry.

\section{Concluding remarks}

The notion of Sharpe performance is easy to interpret in the mean-variance portfolio framework. By considering different information sets, benchmark portfolios and horizons, this measure provides a battery of coherent ranking procedures. These rankings are easy to implement by performing the appropriate regressions and computing the corresponding Sharpe performance measures, as illustrated in the application to hedge funds. The analysis of a battery of various Sharpe performances is clearly the first approach to be applied for hedge fund comparison, especially for retail investors. Moreover, considering jointly several performance measures avoid largely the possibility of manipulation discussed in Goetzmann et al. (2002), $(2007)^{17}$. Indeed, a manipulation to improve one of the measure can have a negative impact on the other ones. In particular, manipulations by means of information-free dynamic strategy are highly diminished when the whole term structure of performance is considered.

However, the Sharpe performance measures considered in this paper have at least three limitations:

i) They assume that the riskfree asset is introduced in the investor portfolio. Without the riskfree asset the formula for the performance decomposition has to be modified and the expression of the fitted performance is not so simple.

ii) They assume that short-sell is allowed for the retail investor. Under short-sell restrictions, the optimization problem has to be solved under positivity constraints on the allocation. This complicates a lot the formulas of the performance and fitted performance. However, this can highlight the discussion on the importance on taking into account the skewness of excess return distribution for retail investor. If short-sell is allowed, the retail investor can balance negative expected excess return by introducing negative allocation of the asset. Thus, with a mean-variance behavior, it is not very sensitive to the skewness features. At the contrary, the effect of skewness will significantly appears if the Sharpe performance is computed under no short-sell restriction. More generally, the standard Sharpe performance is based on myopic portfolio optimization; it does not incorporate the dynamic aspects of the fund manager's invest-

\footnotetext{
${ }^{17}$ Typically, they assume that the funds are ranked by a single valued measure (see condition 1, p. 1506), which eliminate partial ranking associated with a battery of measures.
} 
ment process, that are the allocation updating frequency, the constraints on allocations and its implicit objective function. Intuitively, some benchmark active investment management should have been defined for each management style. A first attempt to account for the dynamic strategy has been done by Lo (2007).

iii) They suppose that the (conditionaly, fitted) mean and variance are appropriate summary statistics for the location and risk parameters of the historical, conditional or residual return distributions. This is not necessarily the case when these distributions feature high skewness and fat tails, since the sample mean is very sensitive to outliers, and the variance is not an appropriate measure of risk. High kurtosis and skewness are generally observed on the unconditional distribution ${ }^{18}$ of hedge funds, which can follow dynamic management strategies. Other historical performance measures have been proposed in the literature [see Farinelli et al. (2008) in the context of optimal allocation]. They are generally obtained by considering a modified ratio, in which the variance (resp. the mean) is replaced by another measure of risk (resp. location). The measure of risk can be based on a Value-at-Risk [see e.g. Dowd (1999), Gregoriou, Gueyie (2003), Amenc, Le Sourd (2005)], a semi-standard deviation [see e.g. Roy (1952), (1956), Bawa (1975), the so-called Sortino ratio : Sortino, Van der Meer (1991), Sortino, Price (2004), used by Harding (2002), Johnson, McLeod, Thomas (2002) and the survey by Pedersen, Satchell (2002)], historical prices of put and call, as in the Omega measure [see e.g. Keating, Shadwick (2002)], a TailVaR [see e.g. Gourieroux, Liu (2007)], or L-moments [Darolles, Gourieroux, Jasiak (2009)]. However, all these alternative measures can only be implemented in practice, if they allow a coherent analysis of historical/conditional, fitted/unfitted measures, as Sharpe performance does. Moreover, it is difficult to believe that they will be understood by retail investors and use in an appropriate way in their portfolio management.

The Sharpe performance based rankings assume that the investor is able to reallocate efficiently his/her portfolio. These rankings can be misleading for an investor, who is allocating his/her portfolio in a naive way. For instance, if two funds have to be included in a portfolio, they do not have to be selected by looking for the largest sum of individual performances $S_{j}+S_{k}$, but for the largest sum $S_{j}+S_{k \mid j}=S_{k}+S_{j \mid k}$ to correct for the possible dependence between returns. To avoid misunderstanding of hedge fund rankings, which are already largely diffused by generalist or specialized newspapers, it is important not only to explain carefully how they are derived, but also how they can be used. In this respect, the knowledge of Sharpe performance, that is $m_{j} / \sigma_{j}$, does not allow to compute the new optimal allocation, that is $m_{j} / \sigma_{j}^{2}$. For deriving this optimal allocation separate information on $m_{j}$ and $\sigma_{j}^{2}$ is also required and generally not provided. In other words, if a high Sharpe ratio is a good thing, a portfolio strategy cannot be based on the Sharpe ratio only.

\footnotetext{
${ }^{18}$ However, fat tails and asymmetries are often highly reduced for conditional distributions.
} 


\section{Appendix 1: Unconditional versus conditional performance}

The unconditional Sharpe ratio is defined by:

$$
S r=\frac{E\left(y_{t+1}\right)}{\left[V\left(y_{t+1}\right)\right]^{1 / 2}}
$$

Let us denote by $m_{t}$ [resp. $\left.\sigma_{t}^{2}\right]$ the conditional expectation $m_{t}=E_{t}\left(y_{t+1}\right)\left[\right.$ resp. $\sigma_{t}^{2}=V_{t}\left(y_{t+1}\right)$ the conditional variance]. By the iterated expectation theorem, we get: $E\left(y_{t+1}\right)=E m_{t}$, and by the variance decomposition equation: $V\left(y_{t+1}\right)=V\left(m_{t}\right)+E\left(\sigma_{t}^{2}\right)$. We deduce that:

$$
S r=\frac{E\left(m_{t}\right)}{\left[V\left(m_{t}\right)+E\left(\sigma_{t}^{2}\right)\right]^{1 / 2}}=\frac{E\left(\sigma_{t} S r_{t}\right)}{\left[V\left(\sigma_{t} S r_{t}\right)+E\left(\sigma_{t}^{2}\right)\right]^{1 / 2}}=E^{Q_{t}}\left(S r_{t}\right) \frac{E\left(\sigma_{t}\right)}{\left[V\left(\sigma_{t} S r_{t}\right)+E\left(\sigma_{t}^{2}\right)\right]^{1 / 2}}
$$

where $S r_{t}=m_{t} / \sigma_{t}$ is the conditional Sharpe ratio, $Q_{t}$ a modified measure with density $\sigma_{t} / E\left(\sigma_{t}\right)$ and the factor $E\left(\sigma_{t}\right) /\left(V\left[\sigma_{t} S r_{t}\right)+E\left(\sigma_{t}^{2}\right)\right]^{1 / 2}$ is smaller than 1, by Cauchy-Schwarz inequality. Thus, the knowledge of the conditional performance $S r_{t}$ is not sufficient to derive the historical performance. In fact the volatility $\sigma_{t}$ has also to be observed.

\section{Appendix 2: Expression of the fitted performance}

We have:

$$
\begin{aligned}
S_{T: j \mid 1} & =\frac{1}{\sigma_{1}^{2} \sigma_{j}^{2}-\sigma_{1 j}^{2}}\left(m_{1}, m_{j}\right)\left(\begin{array}{cc}
\sigma_{j}^{2} & -\sigma_{1 j} \\
-\sigma_{1 j} & \sigma_{1}^{2}
\end{array}\right)\left(\begin{array}{c}
m_{1} \\
m_{j}
\end{array}\right)-\frac{m_{1}^{2}}{\sigma_{1}^{2}} \\
& =\frac{1}{\sigma_{1}^{2} \sigma_{j}^{2}-\sigma_{1 j}^{2}}\left[m_{1}^{2} \sigma_{j}^{2}-2 m_{1} m_{j} \sigma_{1 j}+m_{j}^{2} \sigma_{j}^{2}\right]-\frac{m_{1}^{2}}{\sigma_{1}^{2}} \\
& =\frac{1}{\sigma_{1}^{2} \sigma_{j}^{2}-\sigma_{1 j}^{2}}\left[\sigma_{1}^{2} m_{j}^{2}-2 m_{1} m_{j} \sigma_{1 j}+\frac{\sigma_{1 j}^{2}}{\sigma_{1}^{2}} m_{1}^{2}\right]+\frac{1}{\sigma_{1}^{2} \sigma_{j}^{2}-\sigma_{1 j}^{2}} m_{1}^{2}\left[\sigma_{j}^{2}-\frac{\sigma_{1 j}^{2}}{\sigma_{1}^{2}}\right]-\frac{m_{1}^{2}}{\sigma_{1}^{2}} \\
& =\frac{1}{\sigma_{j}^{2}-\sigma_{1 j}^{2} / \sigma_{1}^{2}}\left[m_{1}-m_{1} \frac{\sigma_{1 j}}{\sigma_{1}^{2}}\right]^{2} .
\end{aligned}
$$

\section{Appendix 3: Student on the intercept coefficient}

Let us consider the regression $y_{j, t}=\delta_{j}+\beta_{j} y_{1 t}+v_{j, t}$. The variance of the OLS estimator of the intercept coefficient is equal to:

$$
V\left(\delta_{j}\right)=\frac{\eta_{j}^{2}}{T}\left(\frac{1}{T} \sum_{t=1}^{T} y_{1 t}^{2}\right) / V_{e} y_{1}
$$

where $V_{e} y_{1}$ denotes the sample variance of $y_{1}$. Thus, the square of the Student on the intercept coefficient, i.e. $t_{j}^{2}=\frac{\widehat{\delta}_{j}^{2}}{V\left(\widehat{\delta}_{j}\right)}$, differs from $\widehat{S}_{t: j \mid 1}$ by the coefficient $\frac{1}{T^{2}} \sum_{t=1}^{T} y_{1 t}^{2} / V_{e} y_{1}$. This multiplicative coefficient depends on the regressor only. In particular $\widehat{S}_{t: j \mid 1}$ and $t_{j}^{2}$ provide the same ranking. 


\section{References}

[1] Agarwal, V., Boyson, N., and N., Naik (2007), Hedge Funds for Retail Investors? An Examination of Hedged Mutual Funds, forthcoming Journal of Financial and Quantitative Analysis.

[2] Agarwal, V., and N., Naik (2000), Multiperiod Performance Persistence Analysis of Hedge Funds, Journal of Financial and Quantitative Analysis, 35, 327-342.

[3] Agarwal, V., and N., Naik (2004), Risks and Portfolio Decisions involving Hedge Funds, Review of Financial Studies, 17, 63-98.

[4] Amenc, N., and V., Le Sourd (2005), Rating the Ratings, Edhec, Risk and Asset Management Research Center, Working Paper.

[5] Bawa, V. (1975), Optimal Rules for Ordering Uncertain Prospects, Journal of Financial Economics, 2, 95-121.

[6] BNY Mellon (2007), Rethinking Performance in the Hedge Fund Industry, The Bank of New York, Working Paper.

[7] Brown, S., and W., Goetzmann (1997), Mutual Fund Styles, Journal of Financial Economics, 43, 373-399.

[8] Brown, S., and W., Goetzmann (2003), Hedge Funds with Style, Journal of Portfolio Management, Winter.

[9] Chen, Z., and P., Knez (1996), Portfolio Performance Measurement, Theory and Applications, Review of Financial Studies, 9, 511-555.

[10] Chen, S., and C., Lee (1986), The Effects of the Sample Size, the Investment Horizon and Market Conditions on the Validity of Composite Performance Measures: A Generalization, Management Science, 32, 1410-1421. 
[11] Darolles, S., and C., Gourieroux (2009), The Effects of Management and Provision Accounts on Hedge Fund Returns, DP CREST.

[12] Darolles, S., Gourieroux, C., and J., Jasiak (2009), L-Performance with an Application to Hedge Funds, forthcoming Journal of Empirical Finance.

[13] Das, N. (2003), Hedge Fund Classification Using K-means Clustering Method, Computing in Economics and Finance, 284.

[14] Daul, S. (2007), Capturing Hedge Fund's Risk, Riskmetrics, Working Paper.

[15] Diez de los Rios, A., and R., Garcia (2005), Assessing and Valuing the Nonlinear Structure of Hedge Funds Returns, DP Montreal University.

[16] Douady, R. (2007), Statistical Analysis of Hedge Fund Returns: Replication and Nonlinearities, Riskdata, Working Paper.

[17] Dowd, K. (1999), A Value-at-Risk Approach to Risk-Return Analysis, Journal of Portfolio Management, 25, 60-67.

[18] Dybvig, P., and S., Ross (1985), The Analytics of Performance Measurement Using a Security Market Line, The Journal of Finance, 60, 401-416.

[19] Edwards, F., and M., Caglayan (2001), Hedge Fund Performance and Manager Skill, The Journal of Future Markets, 21, 1003-1028.

[20] Farinelli, S., Ferreira, M., Rossello, D., Thoeny, M., and L., Tibiletti (2008), Beyond Sharpe Ratio: Optimal Asset allocation using Different Performance Ratios, Journal of Banking and Finance, 32, 2057-2063.

[21] Ferson, W., Foerster, S., and D., Keim (1983), General Tests of Latent Variable Models and Mean-Variance Spanning, Journal of Finance, 48, 131-156. 
[22] Ferson, W., and R., Schadt (1996), Measuring Fund Strategy and Performance in Changing Economic Conditions, Journal of Finance, 51, 425-461.

[23] Getmansky, M., Lo, A., and I., Makarov (2004), An Econometric Analysis of Serial Correlation and Illiquidity in Hedge Fund Returns, Journal of Financial Economics, 74, 529-610.

[24] Gibbons, M., Ross, S., and S., Shanken (1989), A Test of the Efficiency of a Given Portfolio, Econometrica, 57, 1121-1152.

[25] Gibson, R, and S., Gyger (2007), The Style Consistency of Hedge Funds, European Financial Management, 13, 287-308.

[26] Goetzmann, W., Ingersoll, J., Spiegel, M., and I., Welch (2002), Sharpening Sharpe Ratios, Yale ICF DP 02-08.

[27] Goetzmann, W., Ingersoll, J., Spiegel, M., and I., Welch (2007), Portfolio Performance Manipulation and Manipulation-proof Performance Measures, Review of Financial Studies, 20, 1503-1546.

[28] Gourieroux, C., and F., Jouneau (1999), Econometrics of Efficient Fitted Portfolios, Journal of Empirical Finance, 6, 87-118.

[29] Gourieroux, C., and W., Liu (2007), Efficient Portfolio Analysis Using Distortion Risk Measures, CREST DP.

[30] Gregoriou, G., and J., Gueyie (2003), Risk Adjusted Performance of Fund of Funds Using a Modified Sharpe Ratio, The Journal of Wealth Management, Winter.

[31] Gupta, B., Cerrahoglu, B., and A., Daglioglu (2003), Evaluating Hedge Fund Performance: Traditional Versus Conditional Approaches, Journal of Alternative Investments, 6, 7-24.

[32] Harding, D. (2002), Critique of the Sharpe Ratio, Winton capital Management. 
[33] Hodges, C., Taylor, .W, and J., Yoder (1997), Stock, Bonds, the Sharpe Ratio and the Investment Horizon, Financial Analysts Journal, 53, 74-80.

[34] Jensen, M. (1968), The Performance of Mutual Funds in the Period 1945-1964, The Journal of Finance, 23, 389-416.

[35] Jensen, M. (1969), Risk, the Pricing of Capital Assets and the Evaluation of Investment Performance, Journal of Business, 42, 167-247.

[36] Jobson, J., and B., Korkie (1982), Potential Performance and Tests of Portfolio Efficiency, Journal of Financial Economics, 10, 433-466.

[37] Jobson, J., and R., Korkie (1989), A Preference Interpretation of Multivariate Test of Assets Set Interaction, Spanning and Mean-Variance Efficiency, Journal of Financial and Quantitative Analysis, 24, 183-204.

[38] Johnson, D., McLeod, N., and C., Thomas (2002), A Framework for the Interpretation of Excess Downside Deviation, AIMA Newsletter, September.

[39] Jones, A. (1949), Fashions in Forecasting, Fortune.

[40] Kat, H., and J., Miffre (2002), Performance Evaluation and Conditioning Information: The Case of Hedge Funds, Cass Business School, Working Paper.

[41] Kat, H., and H., Palaro (2005), Who Needs Hedge Funds? A Copula-Based Approach to Hedge Fund Return Replication, Cass Business School, Working Paper.

[42] Kat, H., and H., Palaro (2007), Replication-Based Evaluation of Hedge Fund Performance, Cass Business School, Working Paper.

[43] Keating, C., and S., Shadwick (2002), A Universal Performance Measure, Journal of Performance Measurement, 6, 59-84. 
[44] Leland, H. (1999), Beyond Mean-Variance Risk and Performance Measurement in a Nonsymmetrical World, Finance Analysts Journal, 55, 27-36.

[45] Levy, H. (1972), Portfolio Performance and the Investment Horizon, Management Science, 18, 645-653.

[46] Levy, H. (1984), Measuring Risk and Performance Over Alternative Investment Horizons, Financial Analysts Journal, 40, 61-68.

[47] Levy, H., and P., Samuelson (1992), The Capital Asset Pricing Model with Discrete Holding Periods, Management Science, 38, 1529-1542.

[48] Lhabitant, F.S. (2002), Hedge Funds : Myths and Limits, Wiley.

[49] Lo, A. (2002), The Statistics of Sharpe Ratio, Financial Analysts Journal, 58, 36-52.

[50] Lo, A. (2007), Where Do Alphas Come From? A New Measure of the Value of Active Investment Management, MIT Sloan School of Management Working Paper.

[51] Liu, M., and P., Chou (2003), The Pitfall of Using Sharpe Ratio, Finance Letters, 1, 84-89.

[52] Markowitz, H. (1952), Portfolio Selection, The Journal of Finance, 7, 77-91.

[53] McLeod, W., and G., Van Vuuren (2004), Interpreting the Sharpe Ratio when Excess Returns Are Negative, Investment Analysts Journal, 59, 15-20.

[54] Merton, R. (1972), An Analytic Derivation of the Efficient Portfolio Frontier, Journal of Financial and Quantitative Analysis, 7, 1851-1872.

[55] Moix, P., and C., Schmidhuber (2001), Fat-tail Risk. The Case of Hedge Funds, AIMA Newletters, December.

[56] Morningstar (2006), The Morningstar Rating Methodology, available online at http://corporatemorningstar.com/us/documents/MethodologyDocuments/Morningstar FundRat- 
ingMethodology.

[57] Pedersen, C., and S., Satchell (2002), On the Foundation of Performance Measures under Asymmetric Returns, Quantitative Finance, 2, 217-223.

[58] Prigent, J.L. (2007), Portfolio Optimization and Performance Analysis, Chapman \& Hall.

[59] Roll, R. (1978), Ambiguity when Performance is Measured by the Security Market Line, The Journal of Finance, 33, 1051-1069.

[60] Roy, A. (1952), Safety First and the Holding of Assets, Econometrica, 20, 431-439.

[61] Roy, A. (1956), Risk and Rank or Safety First Generalized, Economica, 91, 214-228.

[62] Schneeweis, T., Kazemi, H., Gupta, B., and A., Daglioglu (2003), Benchmarking Hedge Fund Performance with Passive Factor-Based Indexes, Working Paper, CISDM.

[63] Sharpe, W. (1966), Mutual Fund Performance, Journal of Business, 36, 119-138.

[64] Sharpe, W. (1992), Asset Allocation: Management Style and Performance Measurement, Journal of Portfolio Management, 18, 7-19.

[65] Sharpe, W. (1994), The Sharpe Ratio, Journal of Portfolio Management, 21, 49-58.

[66] Sortino, F., and L., Price (1994), Performance Measurement in a Downside Risk Framework, The Journal of Investing, 59-65.

[67] Sortino, F., and R., Van der Meer (1991), Downside Risk, The Journal of Portfolio Management, $27-31$.

[68] Stutzer, M. (2000), A Portfolio Performance Index, Financial Analysts Journal, 56, May-June.

[69] Treynor, J. (1965), How to Rate Management Funds?, Harvard Business Review, XLIII, 63-79. 
[70] Treynor, J., and F., Black (1973), How to Use Security Analysis to Improve Portfolio Selection?, Journal of Business, 66-86.

[71] Treynor, J., and K., Mazuy (1966), Can Mutual Funds Outguess the Market, Harvard Business Review, 44, 131-136. 


\begin{tabular}{|c|c|c|c|c|}
\hline Ticker & Fund Name & Strategy & Manager & Fund Assets \\
\hline GU EH & Exane Investors Gulliver Fund & Equity Hedge & Exane Structured Asset Management & 918048000 \\
\hline $\mathrm{IC} \mathrm{EH}$ & Ibis Capital, LP & Equity Hedge & Ibis Management, LLC & 35000000 \\
\hline OAM EH & Odey European Inc. & Equity Hedge & Odey Asset Management Limited & 637070000 \\
\hline PF EH & Platinum Fund Ltd. & Equity Hedge & Optima Fund Management & 1009357000 \\
\hline PM EH & PM Capital Australian Opportunities Fund Ltd. & Equity Hedge & PM Capital Limited & 19000000 \\
\hline RA EH & RAB Europe Fund & Equity Hedge & RAB Capital plc & 189000000 \\
\hline RB EH & Robeco Boston Partners Long/Short Equity, L.P. & Equity Hedge & Robeco Investment Management & 45990000 \\
\hline SP EH & Sprott Opportunities Hedge Fund, L.P. & Equity Hedge & Sprott Asset Management Inc. & 313000000 \\
\hline $\mathrm{RC} \mathrm{EH}$ & Robbins Capital Partners, L.P. & Equity Hedge & T. Robbins Capital Management, LLC & 25000000 \\
\hline FS EM & Fairfield Sentry Ltd. & Equity Market Neutral & Fairfield Greenwich Group & 6800000000 \\
\hline I EM & Invesco QLS Equity & Equity Market Neutral & Invesco Structured Products Group & 806461000 \\
\hline LC EN & Large Cap Core Equity & Equity Non-Hedge & First Quadrant L.P. & 3063300000 \\
\hline TR EN & Thames River European Fund & Equity Non-Hedge & Thames River Capital LLP & 42888960 \\
\hline LES SS & Leveraged Short Equity Index Hedge L.P. & Short Selling & Derivative Consulting Group L.L.C. & 3000000 \\
\hline APM MA & APM Global Fixed Income Composite Fund & Macro & Absolute Plus Management, LLC & 177000000 \\
\hline AS MA & Aspect Diversified Fund Limited & Macro & Aspect Capital Limited & 1420000000 \\
\hline FO MA & FORT Global Contrarian LP & Macro & Fort, Inc. & 694721000 \\
\hline FX MA & FX Concepts Global Currency Program & Macro & FX Concepts, Inc. & 3600000000 \\
\hline $\mathrm{HC} \mathrm{MA}$ & Haidar Jupiter International Ltd. & Macro & Haidar Capital Management, LLC & 80387000 \\
\hline ML MA & Maple Leaf Macro Volatility Fund & Macro & Maple Leaf Capital & 635000000 \\
\hline PE MA & Permal Global Opportunities Ltd. A & Macro & Permal Asset Management, Inc. & 770000000 \\
\hline WI MA & Winton Futures Fund & Macro & Winton Capital Management & 4440000000 \\
\hline DF MF & Discus Fund Limited & Managed Futures & Capital Fund Management & 47989382 \\
\hline CG RV & Clinton Multistrategy Fund & Relative Value Arbitrage & Clinton Group, Inc. & 685000000 \\
\hline EF RV & Endeavour Fund L.P. & Relative Value Arbitrage & Endeavour Capital LLP & 2767000000 \\
\hline WE RV & Western Investment Institutional Partners, LLC & Relative Value Arbitrage & Western Investment, LLC & 62000000 \\
\hline $\mathrm{AC} \mathrm{CA}$ & Advent Convertible Arbitrage Fund, L.P. & Convertible Arbitrage & Advent Capital Management, LLC & 40000000 \\
\hline AI CA & Aristeia International, Ltd. & Convertible Arbitrage & Aristeia Capital LLC & 2746479000 \\
\hline PI MA & Paulson International Ltd. & Merger Arbitrage & Paulson \& Co., Inc. & 3373000000 \\
\hline CSS ED & Courage Special Situations Offshore Fund, Ltd. & Event-Driven & Courage Capital Management, LLC & 350567000 \\
\hline RO ED & Rosseau Limited Partnership & Event-Driven & Rosseau Asset Management Ltd. & 157263000 \\
\hline TT ED & TT Event-Driven Fund & Event-Driven & TT International & 990006144 \\
\hline $\mathrm{BF}$ FI & BlackRock Fixed Income Global Opportunities Fund LLC & Fixed Income Arbitrage & BlackRock Financial Management, Inc. & 1333000000 \\
\hline BR FI & Blue River Advantaged Muni Fund & Fixed Income Arbitrage & Blue River Asset Management & 1600000000 \\
\hline DM FI & Drake Global Opportunities Fund, Ltd. & Fixed Income Arbitrage & Drake Management LLC & 3896000000 \\
\hline RCG DS & RCG Carpathia Overseas Fund, Ltd. & Distressed Securities & Ramius Capital Group, LLC & 498000000 \\
\hline
\end{tabular}

Table 1: The funds by strategy 


\begin{tabular}{|c|c|c|c|c|c|c|}
\hline \multirow[t]{2}{*}{ Ticker } & \multirow[t]{2}{*}{ Ann. (excess) $\mathbf{m}$} & \multirow[t]{2}{*}{ Ann. $\sigma$} & \multicolumn{2}{|c|}{ SP500 Index } & \multicolumn{2}{|c|}{ Lehman Bond Index } \\
\hline & & & Current $\beta$ & Lagged $\gamma$ & Current $\beta$ & Lagged $\gamma$ \\
\hline GU EH & $2.36 \%$ & $2.47 \%$ & $14.84 \%$ & $-3.03 \%$ & $8.62 \%$ & $13.61 \%$ \\
\hline IC EH & $5.64 \%$ & $11.64 \%$ & $111.51 \%$ & $-33.33 \%$ & $-17.28 \%$ & $75.17 \%$ \\
\hline OAM EH & $8.26 \%$ & $9.21 \%$ & $27.24 \%$ & $1.80 \%$ & $-8.07 \%$ & $-28.39 \%$ \\
\hline PF EH & $7.64 \%$ & $7.08 \%$ & $54.84 \%$ & $5.32 \%$ & $44.63 \%$ & $-3.44 \%$ \\
\hline PM EH & $13.60 \%$ & $5.87 \%$ & $53.02 \%$ & $-4.79 \%$ & $25.45 \%$ & $45.11 \%$ \\
\hline RA EH & $10.06 \%$ & $9.19 \%$ & $64.47 \%$ & $-12.47 \%$ & $2.06 \%$ & $11.99 \%$ \\
\hline $\mathrm{RB} \mathrm{EH}$ & $9.09 \%$ & $5.80 \%$ & $-12.05 \%$ & $6.01 \%$ & $15.84 \%$ & $24.71 \%$ \\
\hline SP EH & $25.59 \%$ & $11.47 \%$ & $39.63 \%$ & $5.80 \%$ & $59.25 \%$ & $31.30 \%$ \\
\hline $\mathrm{RC} \mathrm{EH}$ & $-6.48 \%$ & $16.92 \%$ & $98.66 \%$ & $-42.48 \%$ & $104.78 \%$ & $118.24 \%$ \\
\hline FS EM & $3.64 \%$ & $1.41 \%$ & $2.09 \%$ & $-6.91 \%$ & $-3.61 \%$ & $4.26 \%$ \\
\hline I EM & $13.09 \%$ & $7.77 \%$ & $95.22 \%$ & $-24.86 \%$ & $-20.57 \%$ & $38.99 \%$ \\
\hline LC EN & $10.90 \%$ & $8.15 \%$ & $106.41 \%$ & $-17.56 \%$ & $11.54 \%$ & $39.89 \%$ \\
\hline TR EN & $14.16 \%$ & $9.48 \%$ & $100.08 \%$ & $-12.53 \%$ & $-40.39 \%$ & $26.89 \%$ \\
\hline LES SS & $-12.91 \%$ & $11.19 \%$ & $-151.15 \%$ & $12.30 \%$ & $-13.99 \%$ & $-58.36 \%$ \\
\hline APM MA & $6.55 \%$ & $6.59 \%$ & $11.47 \%$ & $-1.39 \%$ & $-0.03 \%$ & $9.56 \%$ \\
\hline AS MA & $9.76 \%$ & $12.56 \%$ & $91.66 \%$ & $-1.84 \%$ & $-34.83 \%$ & $-36.07 \%$ \\
\hline FO MA & $10.91 \%$ & $6.47 \%$ & $44.67 \%$ & $-13.85 \%$ & $44.08 \%$ & $33.37 \%$ \\
\hline FX MA & $10.31 \%$ & $10.69 \%$ & $72.36 \%$ & $1.57 \%$ & $-24.36 \%$ & $52.87 \%$ \\
\hline HC MA & $9.67 \%$ & $7.82 \%$ & $72.21 \%$ & $-3.82 \%$ & $30.71 \%$ & $11.17 \%$ \\
\hline ML MA & $5.52 \%$ & $5.78 \%$ & $19.35 \%$ & $7.37 \%$ & $23.80 \%$ & $-12.55 \%$ \\
\hline PE MA & $15.32 \%$ & $10.49 \%$ & $72.61 \%$ & $-12.43 \%$ & $52.93 \%$ & $-3.35 \%$ \\
\hline WI MA & $14.36 \%$ & $14.57 \%$ & $96.88 \%$ & $-2.37 \%$ & $48.26 \%$ & $-21.47 \%$ \\
\hline DF MF & $28.13 \%$ & $16.89 \%$ & $58.33 \%$ & $-61.46 \%$ & $-33.97 \%$ & $-100.61 \%$ \\
\hline CG RV & $4.17 \%$ & $4.24 \%$ & $15.72 \%$ & $1.98 \%$ & $16.69 \%$ & $28.48 \%$ \\
\hline EF RV & $0.51 \%$ & $4.31 \%$ & $-9.24 \%$ & $-17.64 \%$ & $5.79 \%$ & $-22.12 \%$ \\
\hline WE RV & $7.33 \%$ & $3.63 \%$ & $2.22 \%$ & $2.02 \%$ & $13.40 \%$ & $0.86 \%$ \\
\hline $\mathrm{AC} \mathrm{CA}$ & $0.68 \%$ & $3.94 \%$ & $21.24 \%$ & $11.45 \%$ & $12.13 \%$ & $30.59 \%$ \\
\hline AI CA & $4.45 \%$ & $3.30 \%$ & $-4.52 \%$ & $6.61 \%$ & $-5.16 \%$ & $14.87 \%$ \\
\hline PI MA & $14.67 \%$ & $8.75 \%$ & $-0.05 \%$ & $16.64 \%$ & $41.22 \%$ & $-27.65 \%$ \\
\hline CSS ED & $5.98 \%$ & $4.92 \%$ & $35.30 \%$ & $8.49 \%$ & $6.57 \%$ & $30.39 \%$ \\
\hline RO ED & $32.34 \%$ & $20.56 \%$ & $75.07 \%$ & $-80.72 \%$ & $57.72 \%$ & $68.75 \%$ \\
\hline TT ED & $12.37 \%$ & $7.61 \%$ & $55.87 \%$ & $20.35 \%$ & $-24.87 \%$ & $26.65 \%$ \\
\hline BF FI & $-0.85 \%$ & $1.03 \%$ & $-0.37 \%$ & $-1.67 \%$ & $14.95 \%$ & $0.05 \%$ \\
\hline BR FI & $9.84 \%$ & $9.70 \%$ & $-15.18 \%$ & $15.16 \%$ & $9.47 \%$ & $15.14 \%$ \\
\hline DM FI & $12.86 \%$ & $11.70 \%$ & $51.78 \%$ & $-30.01 \%$ & $3.01 \%$ & $61.73 \%$ \\
\hline RCG DS & $10.88 \%$ & $7.31 \%$ & $30.67 \%$ & $25.97 \%$ & $35.94 \%$ & $53.88 \%$ \\
\hline
\end{tabular}

Table 2: Summary statistics 


\begin{tabular}{|c|c|c|c|c|c|c|c|c|c|}
\hline \multirow[t]{3}{*}{ Ticker } & \multirow{2}{*}{\multicolumn{2}{|c|}{ Hist. Perf. }} & \multicolumn{7}{|c|}{ Conditional Performance } \\
\hline & & & & arame & & SP & $+1 \%$ & SP & $=-1 \%$ \\
\hline & SR & Rank & $\gamma$ & $\delta$ & Ann. $\sigma$ & SR & Rank & SR & Rank \\
\hline FS EM & 2.57 & 1 & $-6.9 \%$ & $0.3 \%$ & $1.3 \%$ & 2.32 & 1 & 3.73 & 1 \\
\hline PM EH & 2.32 & 2 & $-4.8 \%$ & $1.2 \%$ & $5.9 \%$ & 2.28 & 2 & 2.48 & 2 \\
\hline SP EH & 2.23 & 3 & $5.8 \%$ & $2.1 \%$ & $11.5 \%$ & 2.26 & 3 & 2.14 & 6 \\
\hline WE RV & 2.02 & 4 & $2.0 \%$ & $0.6 \%$ & $3.6 \%$ & 2.05 & 4 & 1.92 & 8 \\
\hline FO MA & 1.69 & 5 & $-13.8 \%$ & $1.0 \%$ & $6.4 \%$ & 1.57 & 9 & 2.11 & 7 \\
\hline I EM & 1.68 & 6 & $-24.9 \%$ & $1.2 \%$ & $7.6 \%$ & 1.52 & 10 & 2.35 & 5 \\
\hline PI MA & 1.68 & 7 & $16.6 \%$ & $1.1 \%$ & $8.7 \%$ & 1.78 & 5 & 1.33 & 16 \\
\hline DF MF & 1.67 & 8 & $-61.5 \%$ & $2.7 \%$ & $16.3 \%$ & 1.48 & 11 & 2.43 & 3 \\
\hline TT ED & 1.63 & 9 & $20.4 \%$ & $0.9 \%$ & $7.5 \%$ & 1.77 & 6 & 1.14 & 19 \\
\hline RO ED & 1.57 & 10 & $-80.7 \%$ & $3.2 \%$ & $19.7 \%$ & 1.37 & 15 & 2.41 & 4 \\
\hline RB EH & 1.57 & 11 & $6.0 \%$ & $0.7 \%$ & $5.8 \%$ & 1.62 & 8 & 1.38 & 13 \\
\hline TR EN & 1.49 & 12 & $-12.5 \%$ & $1.3 \%$ & $9.4 \%$ & 1.42 & 13 & 1.75 & 10 \\
\hline RCG DS & 1.49 & 13 & $26.0 \%$ & $0.8 \%$ & $7.1 \%$ & 1.67 & 7 & 0.85 & 30 \\
\hline PE MA & 1.46 & 14 & $-12.4 \%$ & $1.3 \%$ & $10.5 \%$ & 1.40 & 14 & 1.69 & 11 \\
\hline AI CA & 1.35 & 15 & $6.6 \%$ & $0.3 \%$ & $3.3 \%$ & 1.45 & 12 & 0.98 & 23 \\
\hline $\mathrm{LC} \mathrm{EN}$ & 1.34 & 16 & $-17.6 \%$ & $1.0 \%$ & $8.1 \%$ & 1.22 & 17 & 1.76 & 9 \\
\hline $\mathrm{HC} \mathrm{MA}$ & 1.24 & 17 & $-3.8 \%$ & $0.8 \%$ & $7.8 \%$ & 1.21 & 18 & 1.33 & 17 \\
\hline CSS ED & 1.21 & 18 & $8.5 \%$ & $0.5 \%$ & $4.9 \%$ & 1.30 & 16 & 0.90 & 27 \\
\hline LES SS & 1.15 & 19 & $12.3 \%$ & $-1.1 \%$ & $11.2 \%$ & 1.10 & 20 & 1.36 & 14 \\
\hline DM FI & 1.10 & 20 & $-30.0 \%$ & $1.2 \%$ & $11.5 \%$ & 0.97 & 28 & 1.61 & 12 \\
\hline RA EH & 1.09 & 21 & $-12.5 \%$ & $0.9 \%$ & $9.1 \%$ & 1.02 & 22 & 1.36 & 15 \\
\hline PF EH & 1.08 & 22 & $5.3 \%$ & $0.6 \%$ & $7.1 \%$ & 1.12 & 19 & 0.94 & 24 \\
\hline BR FI & 1.01 & 23 & $15.2 \%$ & $0.7 \%$ & $9.6 \%$ & 1.10 & 21 & 0.73 & 32 \\
\hline APM MA & 0.99 & 24 & $-1.4 \%$ & $0.6 \%$ & $6.6 \%$ & 0.98 & 25 & 1.03 & 21 \\
\hline WI MA & 0.99 & 25 & $-2.4 \%$ & $1.2 \%$ & $14.6 \%$ & 0.98 & 26 & 1.02 & 22 \\
\hline CG RV & 0.98 & 26 & $2.0 \%$ & $0.3 \%$ & $4.2 \%$ & 1.01 & 24 & 0.90 & 28 \\
\hline FX MA & 0.96 & 27 & $1.6 \%$ & $0.9 \%$ & $10.7 \%$ & 0.97 & 27 & 0.94 & 25 \\
\hline GU EH & 0.96 & 28 & $-3.0 \%$ & $0.2 \%$ & $2.5 \%$ & 0.89 & 31 & 1.19 & 18 \\
\hline ML MA & 0.95 & 29 & $7.4 \%$ & $0.4 \%$ & $5.8 \%$ & 1.02 & 23 & 0.72 & 33 \\
\hline OAM EH & 0.90 & 30 & $1.8 \%$ & $0.7 \%$ & $9.2 \%$ & 0.91 & 30 & 0.86 & 29 \\
\hline BF FI & 0.82 & 31 & $-1.7 \%$ & $-0.1 \%$ & $1.0 \%$ & 0.91 & 29 & 0.52 & 34 \\
\hline AS MA & 0.78 & 32 & $-1.8 \%$ & $0.8 \%$ & $12.6 \%$ & 0.77 & 32 & 0.80 & 31 \\
\hline IC EH & 0.48 & 33 & $-33.3 \%$ & $0.7 \%$ & $11.4 \%$ & 0.34 & 34 & 1.04 & 20 \\
\hline $\mathrm{RC} \mathrm{EH}$ & 0.38 & 34 & $-42.5 \%$ & $-0.3 \%$ & $16.6 \%$ & 0.51 & 33 & 0.09 & 36 \\
\hline $\mathrm{AC} \mathrm{CA}$ & 0.17 & 35 & $11.5 \%$ & $0.0 \%$ & $3.8 \%$ & 0.33 & 35 & 0.38 & 35 \\
\hline EF RV & 0.12 & 36 & $-17.6 \%$ & $0.1 \%$ & $4.1 \%$ & 0.10 & 36 & 0.93 & 26 \\
\hline
\end{tabular}

Table 3: Conditional Sharpe Performance with S\&P Benchmark Portfolio $\left(\sqrt{12} S_{j}^{1 / 2}\right.$ are reported) 


\begin{tabular}{|c|c|c|c|c|c|c|c|c|c|}
\hline \multirow[t]{3}{*}{ Ticker } & \multirow{3}{*}{\multicolumn{2}{|c|}{$\begin{array}{l}\text { Hist. Perf. } \\
\text { SR Rank }\end{array}$}} & \multicolumn{7}{|c|}{ Conditional Performance } \\
\hline & & & \multicolumn{3}{|c|}{ Parameters } & \multicolumn{2}{|c|}{$\mathrm{LB}=+1 \%$} & \multicolumn{2}{|c|}{$\mathrm{LB}=-1 \%$} \\
\hline & & & $\gamma$ & $\delta$ & Ann. $\sigma$ & SR & Rank & SR & Rank \\
\hline FS EM & 2.57 & 1 & $4.3 \%$ & $0.3 \%$ & $1.4 \%$ & 2.95 & 2 & 2.22 & 2 \\
\hline PM EH & 2.32 & 2 & $45.1 \%$ & $1.1 \%$ & $5.5 \%$ & 3.43 & 1 & 1.46 & 7 \\
\hline SP EH & 2.23 & 3 & $31.3 \%$ & $2.1 \%$ & $11.4 \%$ & 2.57 & 3 & 1.91 & 5 \\
\hline WE RV & 2.02 & 4 & $0.9 \%$ & $0.6 \%$ & $3.6 \%$ & 2.05 & 9 & 1.99 & 4 \\
\hline FO MA & 1.69 & 5 & $33.4 \%$ & $0.9 \%$ & $6.3 \%$ & 2.35 & 5 & 1.07 & 18 \\
\hline I EM & 1.68 & 6 & $39.0 \%$ & $1.1 \%$ & $7.6 \%$ & 2.33 & 6 & 1.09 & 17 \\
\hline PI MA & 1.68 & 7 & $-27.6 \%$ & $1.2 \%$ & $8.7 \%$ & 1.33 & 22 & 2.09 & 3 \\
\hline DF MF & 1.67 & 8 & $-100.6 \%$ & $2.4 \%$ & $16.2 \%$ & 1.02 & 29 & 2.51 & 1 \\
\hline TT ED & 1.63 & 9 & $26.7 \%$ & $1.0 \%$ & $7.5 \%$ & 2.06 & 8 & 1.21 & 11 \\
\hline RO ED & 1.57 & 10 & $68.7 \%$ & $2.7 \%$ & $20.3 \%$ & 1.98 & 11 & 1.17 & 13 \\
\hline RB EH & 1.57 & 11 & $24.7 \%$ & $0.7 \%$ & $5.7 \%$ & 2.10 & 7 & 1.06 & 20 \\
\hline TR EN & 1.49 & 12 & $26.9 \%$ & $1.2 \%$ & $9.4 \%$ & 1.84 & 15 & 1.15 & 14 \\
\hline RCG DS & 1.49 & 13 & $53.9 \%$ & $0.9 \%$ & $6.9 \%$ & 2.49 & 4 & 0.61 & 29 \\
\hline PE MA & 1.46 & 14 & $-3.3 \%$ & $1.3 \%$ & $10.5 \%$ & 1.42 & 20 & 1.50 & 6 \\
\hline AI CA & 1.35 & 15 & $14.9 \%$ & $0.4 \%$ & $3.2 \%$ & 1.91 & 13 & 0.80 & 26 \\
\hline LC EN & 1.34 & 16 & $39.9 \%$ & $0.9 \%$ & $7.9 \%$ & 1.95 & 12 & 0.75 & 28 \\
\hline $\mathrm{HC}$ MA & 1.24 & 17 & $11.2 \%$ & $0.8 \%$ & $7.8 \%$ & 1.40 & 21 & 1.06 & 19 \\
\hline CSS ED & 1.21 & 18 & $30.4 \%$ & $0.5 \%$ & $4.7 \%$ & 2.01 & 10 & 0.47 & 31 \\
\hline LES SS & 1.15 & 19 & $-58.4 \%$ & $-1.1 \%$ & $10.9 \%$ & 1.81 & 16 & 0.52 & 30 \\
\hline DM FI & 1.10 & 20 & $61.7 \%$ & $1.0 \%$ & $11.3 \%$ & 1.76 & 17 & 0.46 & 32 \\
\hline RA EH & 1.09 & 21 & $12.0 \%$ & $0.8 \%$ & $9.2 \%$ & 1.25 & 24 & 0.93 & 21 \\
\hline PF EH & 1.08 & 22 & $-3.4 \%$ & $0.6 \%$ & $7.1 \%$ & 1.02 & 28 & 1.14 & 16 \\
\hline BR FI & 1.01 & 23 & $15.1 \%$ & $0.8 \%$ & $9.7 \%$ & 1.20 & 25 & 0.82 & 24 \\
\hline APM MA & 0.99 & 24 & $9.6 \%$ & $0.5 \%$ & $6.6 \%$ & 1.16 & 26 & 0.82 & 25 \\
\hline WI MA & 0.99 & 25 & $-21.5 \%$ & $1.2 \%$ & $14.5 \%$ & 0.82 & 31 & 1.17 & 12 \\
\hline CG RV & 0.98 & 26 & $28.5 \%$ & $0.3 \%$ & $4.0 \%$ & 1.85 & 14 & 0.15 & 36 \\
\hline FX MA & 0.96 & 27 & $52.9 \%$ & $0.8 \%$ & $10.4 \%$ & 1.58 & 19 & 0.36 & 33 \\
\hline GU EH & 0.96 & 28 & $13.6 \%$ & $0.2 \%$ & $2.4 \%$ & 1.65 & 18 & 0.28 & 35 \\
\hline ML MA & 0.95 & 29 & $-12.6 \%$ & $0.5 \%$ & $5.8 \%$ & 0.71 & 32 & 1.23 & 10 \\
\hline OAM EH & 0.90 & 30 & $-28.4 \%$ & $0.7 \%$ & $9.1 \%$ & 0.55 & 33 & 1.29 & 9 \\
\hline BF FI & 0.82 & 31 & $0.0 \%$ & $-0.1 \%$ & $1.0 \%$ & 0.82 & 30 & 0.83 & 23 \\
\hline AS MA & 0.78 & 32 & $-36.1 \%$ & $0.8 \%$ & $12.4 \%$ & 0.45 & 35 & 1.15 & 15 \\
\hline IC EH & 0.48 & 33 & $75.2 \%$ & $0.4 \%$ & $11.1 \%$ & 1.29 & 23 & 0.34 & 34 \\
\hline $\mathrm{RC} \mathrm{EH}$ & 0.38 & 34 & $118.2 \%$ & $-0.6 \%$ & $16.0 \%$ & 0.45 & 36 & 1.33 & 8 \\
\hline $\mathrm{AC} \mathrm{CA}$ & 0.17 & 35 & $30.6 \%$ & $0.0 \%$ & $3.7 \%$ & 1.15 & 27 & 0.85 & 22 \\
\hline EF RV & 0.12 & 36 & $-22.1 \%$ & $0.1 \%$ & $4.2 \%$ & 0.49 & 34 & 0.78 & 27 \\
\hline
\end{tabular}

Table 4: Conditional Sharpe Performance with Lehman US Agg Benchmark Portfolio $\left(\sqrt{12} S_{j}^{1 / 2}\right.$ are reported) 


\begin{tabular}{|c|c|c|c|c|c|c|c|c|c|c|c|c|c|}
\hline \multirow[t]{3}{*}{ Ticker } & \multirow{2}{*}{\multicolumn{2}{|c|}{ Hist. Perf. }} & \multirow{2}{*}{\multicolumn{5}{|c|}{ Fitted Performance }} & \multicolumn{6}{|c|}{ Conditionally Fitted Performance } \\
\hline & & & & & & & & & Parar & ters & & SP & $+1 \%$ \\
\hline & SR & Rank & $\beta$ & Ann. $\alpha$ & Ann. $\eta$ & SR & Rank & $\gamma$ & $\beta$ & $\delta$ & Ann. $\eta$ & SR & Rank \\
\hline FS EM & 2.57 & 1 & $2.1 \%$ & $3.5 \%$ & $1.4 \%$ & 2.51 & 2 & $-6.8 \%$ & $1.3 \%$ & $0.3 \%$ & $1.3 \%$ & 2.43 & 3 \\
\hline PM EH & 2.32 & 2 & $53.0 \%$ & $10.7 \%$ & $4.4 \%$ & 2.43 & 3 & $1.8 \%$ & $53.2 \%$ & $0.9 \%$ & $4.4 \%$ & 2.45 & 2 \\
\hline SP EH & 2.23 & 3 & $39.6 \%$ & $23.4 \%$ & $11.1 \%$ & 2.11 & 5 & $10.9 \%$ & $40.9 \%$ & $1.9 \%$ & $11.1 \%$ & 2.16 & 5 \\
\hline WE RV & 2.02 & 4 & $2.2 \%$ & $7.2 \%$ & $3.6 \%$ & 1.99 & 7 & $2.3 \%$ & $2.5 \%$ & $0.6 \%$ & $3.6 \%$ & 2.02 & 7 \\
\hline FO MA & 1.69 & 5 & $44.7 \%$ & $8.5 \%$ & $5.6 \%$ & 1.52 & 11 & $-8.4 \%$ & $43.7 \%$ & $0.8 \%$ & $5.6 \%$ & 1.45 & 14 \\
\hline I EM & 1.68 & 6 & $95.2 \%$ & $7.9 \%$ & $3.4 \%$ & 2.29 & 4 & $-13.2 \%$ & $93.6 \%$ & $0.7 \%$ & $3.3 \%$ & 2.20 & 4 \\
\hline PI MA & 1.68 & 7 & $0.0 \%$ & $14.7 \%$ & $8.8 \%$ & 1.68 & 9 & $16.9 \%$ & $2.0 \%$ & $1.1 \%$ & $8.7 \%$ & 1.78 & 9 \\
\hline DF MF & 1.67 & 8 & $58.3 \%$ & $24.9 \%$ & $16.3 \%$ & 1.53 & 10 & $-55.0 \%$ & $51.8 \%$ & $2.4 \%$ & $15.9 \%$ & 1.41 & 16 \\
\hline TT ED & 1.63 & 9 & $55.9 \%$ & $9.3 \%$ & $6.4 \%$ & 1.45 & 12 & $27.7 \%$ & $59.2 \%$ & $0.6 \%$ & $6.1 \%$ & 1.73 & 11 \\
\hline RO ED & 1.57 & 10 & $75.1 \%$ & $28.2 \%$ & $19.8 \%$ & 1.43 & 15 & $-72.5 \%$ & $66.4 \%$ & $2.8 \%$ & $19.1 \%$ & 1.30 & 17 \\
\hline RB EH & 1.57 & 11 & $-12.0 \%$ & $9.8 \%$ & $5.7 \%$ & 1.70 & 8 & $4.6 \%$ & $-11.5 \%$ & $0.8 \%$ & $5.7 \%$ & 1.74 & 10 \\
\hline TR EN & 1.49 & 12 & $100.1 \%$ & $8.7 \%$ & $6.0 \%$ & 1.44 & 13 & $-0.1 \%$ & $100.1 \%$ & $0.7 \%$ & $6.0 \%$ & 1.44 & 15 \\
\hline RCG DS & 1.49 & 13 & $30.7 \%$ & $9.2 \%$ & $7.0 \%$ & 1.32 & 16 & $30.2 \%$ & $34.3 \%$ & $0.6 \%$ & $6.6 \%$ & 1.60 & 12 \\
\hline PE MA & 1.46 & 14 & $72.6 \%$ & $11.4 \%$ & $9.0 \%$ & 1.25 & 17 & $-3.5 \%$ & $72.2 \%$ & $1.0 \%$ & $9.0 \%$ & 1.24 & 18 \\
\hline AI CA & 1.35 & 15 & $-4.5 \%$ & $4.7 \%$ & $3.3 \%$ & 1.43 & 14 & $6.1 \%$ & $-3.8 \%$ & $0.4 \%$ & $3.3 \%$ & 1.53 & 13 \\
\hline LC EN & 1.34 & 16 & $106.4 \%$ & $5.1 \%$ & $2.4 \%$ & 2.10 & 6 & $-4.4 \%$ & $105.9 \%$ & $0.5 \%$ & $2.4 \%$ & 2.03 & 6 \\
\hline $\mathrm{HC} \mathrm{MA}$ & 1.24 & 17 & $72.2 \%$ & $5.7 \%$ & $5.8 \%$ & 0.99 & 19 & $5.2 \%$ & $72.8 \%$ & $0.4 \%$ & $5.7 \%$ & 1.04 & 21 \\
\hline CSS ED & 1.21 & 18 & $35.3 \%$ & $4.1 \%$ & $4.2 \%$ & 0.97 & 20 & $13.1 \%$ & $36.9 \%$ & $0.3 \%$ & $4.1 \%$ & 1.14 & 20 \\
\hline LES SS & 1.15 & 19 & $-151.2 \%$ & $-4.6 \%$ & $1.7 \%$ & 2.74 & 1 & $-6.6 \%$ & $-151.9 \%$ & $-0.3 \%$ & $1.6 \%$ & 3.03 & 1 \\
\hline DM FI & 1.10 & 20 & $51.8 \%$ & $10.0 \%$ & $11.1 \%$ & 0.91 & 22 & $-23.9 \%$ & $48.9 \%$ & $1.0 \%$ & $10.9 \%$ & 0.82 & 28 \\
\hline RA EH & 1.09 & 21 & $64.5 \%$ & $6.5 \%$ & $7.9 \%$ & 0.83 & 23 & $-4.5 \%$ & $63.9 \%$ & $0.6 \%$ & $7.9 \%$ & 0.80 & 29 \\
\hline PF EH & 1.08 & 22 & $54.8 \%$ & $4.6 \%$ & $5.8 \%$ & 0.79 & 27 & $12.3 \%$ & $56.3 \%$ & $0.3 \%$ & $5.8 \%$ & 0.90 & 23 \\
\hline BR FI & 1.01 & 23 & $-15.2 \%$ & $10.7 \%$ & $9.6 \%$ & 1.11 & 18 & $13.5 \%$ & $-13.6 \%$ & $0.8 \%$ & $9.6 \%$ & 1.18 & 19 \\
\hline APM MA & 0.99 & 24 & $11.5 \%$ & $5.9 \%$ & $6.5 \%$ & 0.91 & 21 & $0.0 \%$ & $11.5 \%$ & $0.5 \%$ & $6.5 \%$ & 0.91 & 22 \\
\hline WI MA & 0.99 & 25 & $96.9 \%$ & $9.1 \%$ & $12.7 \%$ & 0.71 & 30 & $9.8 \%$ & $98.0 \%$ & $0.7 \%$ & $4.8 \%$ & 2.00 & 8 \\
\hline CG RV & 0.98 & 26 & $15.7 \%$ & $3.3 \%$ & $4.1 \%$ & 0.81 & 24 & $4.0 \%$ & $16.2 \%$ & $0.3 \%$ & $4.1 \%$ & 0.86 & 27 \\
\hline FX MA & 0.96 & 27 & $72.4 \%$ & $6.3 \%$ & $9.3 \%$ & 0.68 & 32 & $10.7 \%$ & $73.6 \%$ & $0.5 \%$ & $9.3 \%$ & 0.74 & 31 \\
\hline GU EH & 0.96 & 28 & $14.8 \%$ & $1.5 \%$ & $2.2 \%$ & 0.70 & 31 & $-1.2 \%$ & $14.7 \%$ & $0.1 \%$ & $2.2 \%$ & 0.67 & 32 \\
\hline ML MA & 0.95 & 29 & $19.4 \%$ & $4.5 \%$ & $5.6 \%$ & 0.80 & 26 & $9.9 \%$ & $20.5 \%$ & $0.3 \%$ & $5.6 \%$ & 0.88 & 25 \\
\hline OAM EH & 0.90 & 30 & $27.2 \%$ & $6.8 \%$ & $9.0 \%$ & 0.75 & 29 & $5.3 \%$ & $27.9 \%$ & $0.5 \%$ & $9.0 \%$ & 0.78 & 30 \\
\hline BF FI & 0.82 & 31 & $-0.4 \%$ & $-0.8 \%$ & $1.0 \%$ & 0.80 & 25 & $-1.7 \%$ & $-0.6 \%$ & $-0.1 \%$ & $1.0 \%$ & 0.89 & 24 \\
\hline AS MA & 0.78 & 32 & $91.7 \%$ & $4.8 \%$ & $10.6 \%$ & 0.45 & 33 & $9.7 \%$ & $92.8 \%$ & $0.3 \%$ & $10.6 \%$ & 0.49 & 33 \\
\hline IC EH & 0.48 & 33 & $111.5 \%$ & $-0.5 \%$ & $8.3 \%$ & 0.05 & 36 & $-19.8 \%$ & $109.1 \%$ & $0.1 \%$ & $8.2 \%$ & 0.17 & 34 \\
\hline $\mathrm{RC} \mathrm{EH}$ & 0.38 & 34 & $98.7 \%$ & $-11.9 \%$ & $15.3 \%$ & 0.78 & 28 & $-30.7 \%$ & $95.0 \%$ & $-0.8 \%$ & $15.1 \%$ & 0.88 & 26 \\
\hline $\mathrm{AC} C \mathrm{CA}$ & 0.17 & 35 & $21.2 \%$ & $-0.5 \%$ & $3.6 \%$ & 0.13 & 35 & $14.3 \%$ & $22.9 \%$ & $-0.1 \%$ & $3.5 \%$ & 0.05 & 35 \\
\hline EF RV & 0.12 & 36 & $-9.2 \%$ & $1.0 \%$ & $4.3 \%$ & 0.24 & 34 & $-19.1 \%$ & $-11.5 \%$ & $0.2 \%$ & $4.0 \%$ & 0.04 & 36 \\
\hline
\end{tabular}

Table 5: Fitted Performance and Ranking with S\&P Benchmark Portfolio $\left(\sqrt{12} S_{j: E}\right.$ are reported) 


\begin{tabular}{|c|c|c|c|c|c|c|c|c|c|c|c|c|c|}
\hline \multirow[t]{3}{*}{ Ticker } & \multirow{2}{*}{\multicolumn{2}{|c|}{ Hist. Perf. }} & \multirow{2}{*}{\multicolumn{5}{|c|}{ Fitted Performance }} & \multicolumn{6}{|c|}{ Conditionally Fitted Performance } \\
\hline & & & & & & & & & Para & eters & & LB & $+1 \%$ \\
\hline & SR & Rank & $\beta$ & Ann. $\alpha$ & Ann. $\eta$ & SR & Rank & $\gamma$ & $\beta$ & $\delta$ & Ann. $\eta$ & SR & Rank \\
\hline FS EM & 2.57 & 1 & $-3.6 \%$ & $3.6 \%$ & $1.4 \%$ & 2.59 & 1 & $4.7 \%$ & $-4.1 \%$ & $0.3 \%$ & $1.4 \%$ & 3.01 & 2 \\
\hline PM EH & 2.32 & 2 & $25.4 \%$ & $13.6 \%$ & $5.7 \%$ & 2.36 & 2 & $42.9 \%$ & $21.1 \%$ & $1.1 \%$ & $5.4 \%$ & 3.44 & 1 \\
\hline SP EH & 2.23 & 3 & $59.3 \%$ & $25.5 \%$ & $11.1 \%$ & 2.29 & 3 & $25.4 \%$ & $56.7 \%$ & $2.1 \%$ & $11.1 \%$ & 2.57 & 3 \\
\hline WE RV & 2.02 & 4 & $13.4 \%$ & $7.3 \%$ & $3.6 \%$ & 2.05 & 4 & $-0.5 \%$ & $13.5 \%$ & $0.6 \%$ & $3.6 \%$ & 2.03 & 9 \\
\hline FO MA & 1.69 & 5 & $44.1 \%$ & $10.9 \%$ & $6.1 \%$ & 1.77 & 5 & $29.1 \%$ & $41.1 \%$ & $0.9 \%$ & $6.0 \%$ & 2.38 & 6 \\
\hline I EM & 1.68 & 6 & $-20.6 \%$ & $13.1 \%$ & $7.7 \%$ & 1.70 & 7 & $41.6 \%$ & $-24.8 \%$ & $1.1 \%$ & $7.5 \%$ & 2.40 & 5 \\
\hline PI MA & 1.68 & 7 & $41.2 \%$ & $14.6 \%$ & $8.5 \%$ & 1.71 & 6 & $-32.3 \%$ & $44.5 \%$ & $1.2 \%$ & $8.4 \%$ & 1.30 & 24 \\
\hline DF MF & 1.67 & 8 & $-34.0 \%$ & $28.2 \%$ & $16.8 \%$ & 1.68 & 8 & $-98.1 \%$ & $-23.9 \%$ & $2.4 \%$ & $16.2 \%$ & 1.04 & 29 \\
\hline TT ED & 1.63 & 9 & $-24.9 \%$ & $12.4 \%$ & $7.5 \%$ & 1.65 & 9 & $29.5 \%$ & $-27.9 \%$ & $1.0 \%$ & $7.4 \%$ & 2.14 & 7 \\
\hline RO ED & 1.57 & 10 & $57.7 \%$ & $32.3 \%$ & $20.4 \%$ & 1.58 & 10 & $63.4 \%$ & $51.2 \%$ & $2.7 \%$ & $20.2 \%$ & 1.96 & 11 \\
\hline $\mathrm{RB}$ EH & 1.57 & 11 & $15.8 \%$ & $9.1 \%$ & $5.8 \%$ & 1.58 & 11 & $23.3 \%$ & $13.5 \%$ & $0.7 \%$ & $5.6 \%$ & 2.08 & 8 \\
\hline TR EN & 1.49 & 12 & $-40.4 \%$ & $14.2 \%$ & $9.3 \%$ & 1.53 & 12 & $31.4 \%$ & $-43.6 \%$ & $1.2 \%$ & $9.2 \%$ & 1.94 & 13 \\
\hline RCG DS & 1.49 & 13 & $35.9 \%$ & $10.8 \%$ & $7.1 \%$ & 1.52 & 13 & $50.7 \%$ & $30.8 \%$ & $0.9 \%$ & $6.7 \%$ & 2.49 & 4 \\
\hline PE MA & 1.46 & 14 & $52.9 \%$ & $15.3 \%$ & $10.2 \%$ & 1.50 & 14 & $-8.9 \%$ & $53.8 \%$ & $1.3 \%$ & $10.2 \%$ & 1.40 & 20 \\
\hline AI CA & 1.35 & 15 & $-5.2 \%$ & $4.5 \%$ & $3.3 \%$ & 1.35 & 15 & $15.6 \%$ & $-6.7 \%$ & $0.4 \%$ & $3.2 \%$ & 1.95 & 12 \\
\hline LC EN & 1.34 & 16 & $11.5 \%$ & $10.9 \%$ & $8.1 \%$ & 1.34 & 16 & $39.1 \%$ & $7.5 \%$ & $0.9 \%$ & $7.9 \%$ & 1.94 & 14 \\
\hline $\mathrm{HC} \mathrm{MA}$ & 1.24 & 17 & $30.7 \%$ & $9.6 \%$ & $7.7 \%$ & 1.25 & 17 & $8.1 \%$ & $29.9 \%$ & $0.8 \%$ & $7.7 \%$ & 1.38 & 21 \\
\hline CSS ED & 1.21 & 18 & $6.6 \%$ & $6.0 \%$ & $4.9 \%$ & 1.22 & 18 & $30.0 \%$ & $3.5 \%$ & $0.5 \%$ & $4.7 \%$ & 2.00 & 10 \\
\hline LES SS & 1.15 & 19 & $-14.0 \%$ & $-12.9 \%$ & $11.2 \%$ & 1.15 & 19 & $-57.5 \%$ & $-8.1 \%$ & $-1.1 \%$ & $10.8 \%$ & 1.80 & 16 \\
\hline DM FI & 1.10 & 20 & $3.0 \%$ & $12.9 \%$ & $11.7 \%$ & 1.10 & 22 & $62.1 \%$ & $-3.3 \%$ & $1.0 \%$ & $11.3 \%$ & 1.77 & 17 \\
\hline RA EH & 1.09 & 21 & $2.1 \%$ & $10.1 \%$ & $9.2 \%$ & 1.09 & 23 & $11.9 \%$ & $0.8 \%$ & $0.8 \%$ & $9.2 \%$ & 1.25 & 25 \\
\hline $\mathrm{PF}$ EH & 1.08 & 22 & $44.6 \%$ & $7.6 \%$ & $6.8 \%$ & 1.12 & 21 & $-8.2 \%$ & $45.5 \%$ & $0.6 \%$ & $6.8 \%$ & 0.98 & 30 \\
\hline BR FI & 1.01 & 23 & $9.5 \%$ & $9.8 \%$ & $9.7 \%$ & 1.01 & 24 & $14.3 \%$ & $8.0 \%$ & $0.8 \%$ & $9.7 \%$ & 1.19 & 26 \\
\hline APM MA & 0.99 & 24 & $0.0 \%$ & $6.5 \%$ & $6.6 \%$ & 0.99 & 27 & $9.7 \%$ & $-1.0 \%$ & $0.5 \%$ & $6.6 \%$ & 1.17 & 27 \\
\hline WI MA & 0.99 & 25 & $48.3 \%$ & $14.3 \%$ & $14.4 \%$ & 0.99 & 26 & $-26.7 \%$ & $51.0 \%$ & $1.2 \%$ & $14.3 \%$ & 0.78 & 31 \\
\hline CG RV & 0.98 & 26 & $16.7 \%$ & $4.2 \%$ & $4.2 \%$ & 1.00 & 25 & $27.0 \%$ & $13.9 \%$ & $0.3 \%$ & $4.0 \%$ & 1.83 & 15 \\
\hline FX MA & 0.96 & 27 & $-24.4 \%$ & $10.3 \%$ & $10.6 \%$ & 0.97 & 28 & $56.0 \%$ & $-30.1 \%$ & $0.8 \%$ & $10.3 \%$ & 1.63 & 18 \\
\hline GU EH & 0.96 & 28 & $8.6 \%$ & $2.4 \%$ & $2.4 \%$ & 0.97 & 30 & $12.8 \%$ & $7.3 \%$ & $0.2 \%$ & $2.4 \%$ & 1.63 & 19 \\
\hline ML MA & 0.95 & 29 & $23.8 \%$ & $5.5 \%$ & $5.7 \%$ & 0.97 & 29 & $-15.2 \%$ & $25.3 \%$ & $0.5 \%$ & $5.6 \%$ & 0.67 & 32 \\
\hline OAM EH & 0.90 & 30 & $-8.1 \%$ & $8.3 \%$ & $9.2 \%$ & 0.90 & 31 & $-27.8 \%$ & $-5.2 \%$ & $0.7 \%$ & $9.1 \%$ & 0.55 & 33 \\
\hline BF FI & 0.82 & 31 & $14.9 \%$ & $-0.9 \%$ & $0.8 \%$ & 1.14 & 20 & $-1.5 \%$ & $15.1 \%$ & $-0.1 \%$ & $0.8 \%$ & 1.38 & 22 \\
\hline AS MA & 0.78 & 32 & $-34.8 \%$ & $9.8 \%$ & $12.5 \%$ & 0.79 & 32 & $-32.8 \%$ & $-31.5 \%$ & $0.8 \%$ & $12.4 \%$ & 0.49 & 35 \\
\hline IC EH & 0.48 & 33 & $-17.3 \%$ & $5.7 \%$ & $11.6 \%$ & 0.49 & 33 & $77.8 \%$ & $-25.2 \%$ & $0.4 \%$ & $11.0 \%$ & 1.33 & 23 \\
\hline $\mathrm{RC} \mathrm{EH}$ & 0.38 & 34 & $104.8 \%$ & $-6.6 \%$ & $16.2 \%$ & 0.41 & 34 & $108.5 \%$ & $93.7 \%$ & $-0.6 \%$ & $15.4 \%$ & 0.39 & 36 \\
\hline $\mathrm{AC} \mathrm{CA}$ & 0.17 & 35 & $12.1 \%$ & $0.7 \%$ & $3.9 \%$ & 0.17 & 35 & $29.6 \%$ & $9.1 \%$ & $0.0 \%$ & $3.6 \%$ & 1.12 & 28 \\
\hline EF RV & 0.12 & 36 & $5.8 \%$ & $0.5 \%$ & $4.3 \%$ & 0.12 & 36 & $-23.0 \%$ & $8.1 \%$ & $0.1 \%$ & $4.2 \%$ & 0.51 & 34 \\
\hline
\end{tabular}

Table 6: Fitted Performance and Ranking with Lehmann US Agg Benchmark Portfolio $\left(\sqrt{12} S_{j: B}\right.$ are reported) 


\begin{tabular}{|c|c|cc|cc|}
\hline Number & Total inertia & \multicolumn{2}{|c|}{ Within cluster inertia } & \multicolumn{2}{c|}{ Between cluster inertia } \\
\hline & & Value & $\mathbf{\%}$ & Value & \% \\
5 & 1.598 & 0.304 & $19.05 \%$ & 1.294 & $80.95 \%$ \\
6 & 1.598 & 0.235 & $14.73 \%$ & 1.363 & $85.27 \%$ \\
7 & 1.598 & 0.170 & $10.63 \%$ & 1.428 & $89.37 \%$ \\
8 & 1.598 & 0.127 & $7.94 \%$ & 1.471 & $92.06 \%$ \\
9 & 1.598 & 0.094 & $5.91 \%$ & 1.504 & $94.09 \%$ \\
$\mathbf{1 0}$ & $\mathbf{1 . 5 9 8}$ & $\mathbf{0 . 0 8 0}$ & $\mathbf{5 . 0 3 \%}$ & $\mathbf{1 . 5 1 8}$ & $\mathbf{9 4 . 9 7 \%}$ \\
11 & 1.598 & 0.068 & $4.24 \%$ & 1.530 & $95.76 \%$ \\
12 & 1.598 & 0.057 & $3.55 \%$ & 1.541 & $96.45 \%$ \\
13 & 1.598 & 0.046 & $2.87 \%$ & 1.552 & $97.13 \%$ \\
14 & 1.598 & 0.038 & $2.36 \%$ & 1.560 & $97.64 \%$ \\
15 & 1.598 & 0.031 & $1.92 \%$ & 1.567 & $98.08 \%$ \\
\hline
\end{tabular}

Table 7: Inertia decomposition as function of the number of clusters 


\begin{tabular}{|c|c|c|c|c|}
\hline Cluster & Count & Min Perf. & Mean Perf. & Max Perf. \\
\hline 1 & $\mathbf{2}$ & 19,38 & 19,64 & 19,91 \\
\hline 2 & $\mathbf{8}$ & 7,80 & 9,69 & 14,27 \\
\hline 3 & $\mathbf{4 9}$ & 3,31 & 4,13 & 6,29 \\
\hline 4 & $\mathbf{1 2 0}$ & 2,31 & 2,66 & 3,22 \\
\hline 5 & $\mathbf{5 0 0}$ & 1,45 & 1,78 & 2,29 \\
\hline 6 & $\mathbf{5 9 0}$ & 0,86 & 1,14 & 1,44 \\
\hline 7 & $\mathbf{3 4 7}$ & 0,53 & 0,69 & 0,86 \\
\hline 8 & $\mathbf{4 0 5}$ & $-0,01$ & 0,28 & 0,53 \\
\hline 9 & $\mathbf{2 4 4}$ & $-1,21$ & $-0,41$ & $-0,02$ \\
\hline 10 & $\mathbf{2 9}$ & $-5,35$ & $-2,36$ & $-1,28$ \\
\hline
\end{tabular}

Table 8: Cluster description for Historical Sharpe Ratio 


\begin{tabular}{|c|c|c|c|c|c|c|c|c|}
\hline Cluster & \multicolumn{4}{|c|}{ Fitted Sharpe Ratio (SP500) } & \multicolumn{4}{c|}{ Fitted Sharpe Ratio (Bond) } \\
& Count & Min Perf. & Mean Perf. & Max Perf. & Count & Min Perf. & Mean Perf. & Max Perf. \\
\hline 1 & $\mathbf{2}$ & 19,43 & 19,69 & 19,94 & $\mathbf{2}$ & 20,08 & 20,08 & 20,09 \\
\hline 2 & $\mathbf{2}$ & 11,91 & 13,11 & 14,31 & $\mathbf{8}$ & 7,81 & 9,97 & 14,70 \\
\hline 3 & $\mathbf{1 1}$ & 6,15 & 7,67 & 9,61 & $\mathbf{5 7}$ & 3,24 & 4,11 & 6,38 \\
\hline 4 & $\mathbf{2 4}$ & 3,83 & 4,33 & 5,66 & $\mathbf{1 9 6}$ & 2,10 & 2,49 & 3,21 \\
\hline 5 & $\mathbf{1 3 2}$ & 2,32 & 2,81 & 3,73 & $\mathbf{4 5 9}$ & 1,41 & 1,71 & 2,09 \\
\hline 6 & $\mathbf{5 2 6}$ & 1,30 & 1,69 & 2,30 & $\mathbf{5 1 6}$ & 0,91 & 1,16 & 1,41 \\
\hline 7 & $\mathbf{5 1 7}$ & 0,74 & 1,00 & 1,30 & $\mathbf{3 9 7}$ & 0,52 & 0,71 & 0,90 \\
\hline 8 & $\mathbf{6 8 7}$ & $-0,04$ & 0,35 & 0,74 & $\mathbf{5 3 3}$ & $-0,47$ & 0,14 & 0,52 \\
\hline 9 & $\mathbf{3 7 5}$ & $-1,85$ & $-0,48$ & $-0,04$ & $\mathbf{1 0 5}$ & $-1,51$ & $-0,80$ & $-0,48$ \\
\hline 10 & $\mathbf{1 8}$ & $-5,65$ & $-3,04$ & $-2,04$ & $\mathbf{2 1}$ & $-5,49$ & $-2,76$ & $-1,70$ \\
\hline
\end{tabular}

Table 9: Cluster description for Fitted Sharpe Ratios 


\begin{tabular}{|c|cccc|ccc|}
\hline Cluster & \multicolumn{3}{|c}{ Cond. Fitted Sharpe Ratio (SP500) } & \multicolumn{3}{c|}{ Cond. Fitted Sharpe Ratio (Bond) } \\
& Count & Min Perf. & Mean Perf. & Max Perf. & Count & Min Perf. & Mean Perf. \\
Max Perf.
\end{tabular}

Table 10: Cluster description for Cond. Fitted Sharpe Ratios 


\begin{tabular}{|c|c|lc|lc|}
\hline Number & Total inertia & \multicolumn{2}{|c|}{ Within cluster inertia } & \multicolumn{2}{c|}{ Between cluster inertia } \\
\hline & & Value & \% & Value & \% \\
5 & 8.662 & 7.389 & $85.31 \%$ & 1.273 & $14.69 \%$ \\
6 & 8.662 & 7.248 & $83.67 \%$ & 1.414 & $16.33 \%$ \\
7 & 8.662 & 5.549 & $64.07 \%$ & 3.113 & $35.93 \%$ \\
8 & 8.662 & 4.946 & $57.10 \%$ & 3.716 & $42.90 \%$ \\
9 & 8.662 & 3.832 & $44.24 \%$ & 4.830 & $55.76 \%$ \\
$\mathbf{1 0}$ & $\mathbf{8 . 6 6 2}$ & $\mathbf{3 . 6 7 5}$ & $\mathbf{4 2 . 4 3 \%}$ & $\mathbf{4 . 9 8 7}$ & $\mathbf{5 7 . 5 7 \%}$ \\
11 & 8.662 & 3.530 & $40.76 \%$ & 5.132 & $59.24 \%$ \\
12 & 8.662 & 3.419 & $39.47 \%$ & 5.243 & $60.53 \%$ \\
13 & 8.662 & 3.381 & $39.04 \%$ & 5.281 & $60.96 \%$ \\
14 & 8.662 & 3.093 & $35.71 \%$ & 5.569 & $64.29 \%$ \\
15 & 8.662 & 3.074 & $35.49 \%$ & 5.588 & $64.51 \%$ \\
\hline
\end{tabular}

Table 11: Inertia decomposition with cluster number - All performance measures 


\begin{tabular}{|c|c|c|c|c|c|c|c|c|c|c|}
\hline \multirow[t]{2}{*}{ Count } & \multicolumn{2}{|c|}{ Historical SR } & \multicolumn{2}{|c|}{ Fitted SR (SP500) } & \multicolumn{2}{|c|}{ Fitted SR (Bond) } & \multicolumn{2}{|c|}{ Cond. Fitted SR (SP500) } & \multicolumn{2}{|c|}{ Cond. Fitted SR (Bond) } \\
\hline & Min Perf. & Max Perf. & Min Perf. & Max Perf. & Min Perf. & Max Perf. & Min Perf. & Max Perf. & Min Perf. & Max Perf. \\
\hline 3 & 14,27 & 19,91 & 14,31 & 19,94 & 14,70 & 20,09 & 14,24 & 20,32 & 14,08 & 19,84 \\
\hline 2 & 3,95 & 11,72 & 3,89 & $\overline{11,91}$ & 5,16 & 12,75 & 3,92 & 12,18 & 3,47 & 11,58 \\
\hline 46 & 2,71 & 9,37 & 2,61 & 9,61 & 2,71 & 9,58 & 2,24 & 9,60 & 2,54 & 9,10 \\
\hline 71 & 0,87 & 5,05 & 0,69 & 5,01 & 0,99 & 5,61 & 0,07 & 5,62 & 0,52 & 4,57 \\
\hline 180 & $-1,33$ & 3,58 & $-1,49$ & 3,84 & $-1,34$ & 3,59 & $-0,70$ & 4,56 & $-2,07$ & 3,12 \\
\hline 555 & $-2,39$ & 3,81 & $-2,58$ & 3,97 & $-2,39$ & 3,91 & $-3,69$ & 3,23 & $-2,92$ & 3,34 \\
\hline 451 & $-1,95$ & 2,70 & $-2,74$ & 2,59 & $-1,95$ & 2,70 & $-1,73$ & 3,31 & $-1,40$ & 3,29 \\
\hline 416 & $-1,03$ & 4,11 & $-1,22$ & 4,35 & $-1,03$ & 4,24 & $-2,53$ & 2,71 & $-0,80$ & 4,96 \\
\hline 278 & $-0,74$ & 1,64 & $-1,21$ & 1,47 & $-0,78$ & 1,70 & $-1,55$ & 1,58 & $-1,16$ & 1,59 \\
\hline 292 & $-5,35$ & 1,53 & $-5,65$ & 1,68 & $-5,49$ & 1,55 & $-5,39$ & 2,44 & $-6,20$ & 2,34 \\
\hline
\end{tabular}

Table 12: Cluster description projected on each Sharpe Ratio 


\begin{tabular}{|r|c|c|c|c|c|c|c|c|c|c|}
\hline Cluster & $\mathbf{1}$ & $\mathbf{2}$ & $\mathbf{3}$ & $\mathbf{4}$ & $\mathbf{5}$ & $\mathbf{6}$ & $\mathbf{7}$ & $\mathbf{8}$ & $\mathbf{9}$ & $\mathbf{1 0}$ \\
\hline Equity Hedge & 0 & 0 & 2 & 5 & 49 & 170 & 179 & 121 & 98 & 43 \\
Equity Market Neutral & 0 & 0 & 1 & 4 & 20 & 14 & 23 & 24 & 6 & 40 \\
Equity Non-Hedge & 0 & 0 & 0 & 0 & 9 & 18 & 30 & 15 & 24 & 1 \\
Short Selling & 0 & 0 & 0 & 0 & 0 & 0 & 1 & 1 & 0 & 12 \\
Macro & 0 & 0 & 0 & 1 & 14 & 16 & 26 & 40 & 23 & 41 \\
Managed Futures & 0 & 0 & 0 & 2 & 2 & 9 & 27 & 54 & 43 & 36 \\
Foreign Exchange & 0 & 0 & 0 & 1 & 1 & 3 & 7 & 7 & 5 & 18 \\
Market Timing & 0 & 0 & 3 & 0 & 1 & 1 & 8 & 5 & 0 & 1 \\
Relative Value Arbitrage & 0 & 0 & 9 & 4 & 15 & 48 & 18 & 28 & 3 & 0 \\
Convertible Arbitrage & 2 & 0 & 3 & 0 & 0 & 42 & 1 & 14 & 6 & 12 \\
Merger Arbitrage & 0 & 0 & 0 & 1 & 2 & 12 & 2 & 9 & 9 & 28 \\
Event-Driven & 0 & 0 & 2 & 8 & 8 & 71 & 8 & 10 & 23 & 6 \\
Fixed Income Arbitrage & 0 & 1 & 14 & 19 & 20 & 37 & 13 & 26 & 5 & 40 \\
Distressed Securities & 0 & 0 & 4 & 15 & 4 & 41 & 6 & 13 & 3 & 0 \\
Regulation D & 0 & 0 & 2 & 3 & 3 & 4 & 0 & 5 & 2 & 0 \\
Emerging Markets & 0 & 1 & 1 & 8 & 20 & 41 & 46 & 26 & 4 & 5 \\
Sector & 1 & 0 & 5 & 0 & 12 & 28 & 56 & 18 & 24 & 9 \\
\hline Count & $\mathbf{3}$ & $\mathbf{2}$ & $\mathbf{4 6}$ & $\mathbf{7 1}$ & $\mathbf{1 8 0}$ & $\mathbf{5 5 5}$ & $\mathbf{4 5 1}$ & $\mathbf{4 1 6}$ & $\mathbf{2 7 8}$ & $\mathbf{2 9 2}$ \\
\hline
\end{tabular}

Table 13: Self-Declared Strategies Comparison 


\begin{tabular}{|r|c|c|c|c|c|c|c|}
\hline Cluster & $\{\mathbf{1 , 2 , 3 , 4}\}$ & $\mathbf{5}$ & $\mathbf{6}$ & $\mathbf{7}$ & $\mathbf{8}$ & $\mathbf{9}$ & $\mathbf{1 0}$ \\
\hline Equity Hedge & 12.95 & 0.39 & 15.82 & 13.12 & 1.48 & 0.86 & 34.12 \\
Equity Market Neutral & 0 & 8.35 & 4.72 & 0.61 & 0.28 & 7.70 & 19.46 \\
Macro & 4.20 & 0.09 & 6.73 & 1.48 & 1.67 & 0.10 & 10.90 \\
Managed Futures & 3.10 & 10.18 & 17.03 & 2.01 & 10.25 & 17.03 & 3.45 \\
Fixed Income Arbitrage & 114.89 & 2.52 & 0.51 & 14.57 & 2.52 & 14.48 & 6.55 \\
\hline
\end{tabular}

Table 14: Decomposition of the chi-square statistic 


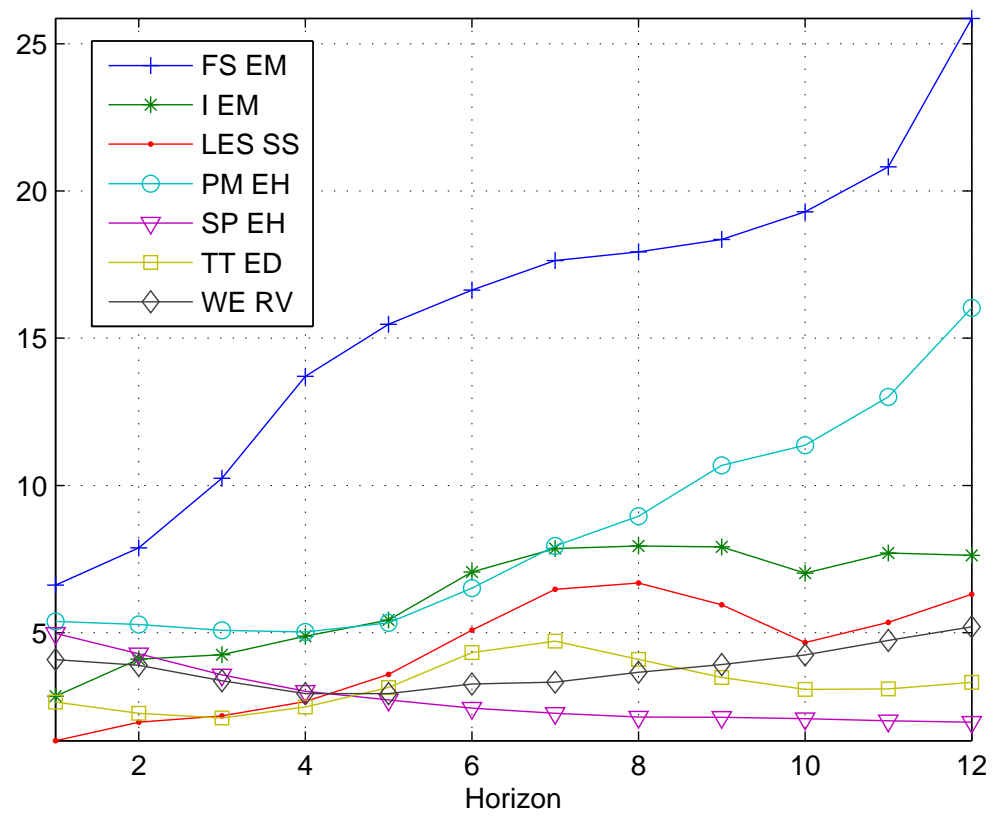

Figure 1: Term Structure of Historical Sharpe Performances 


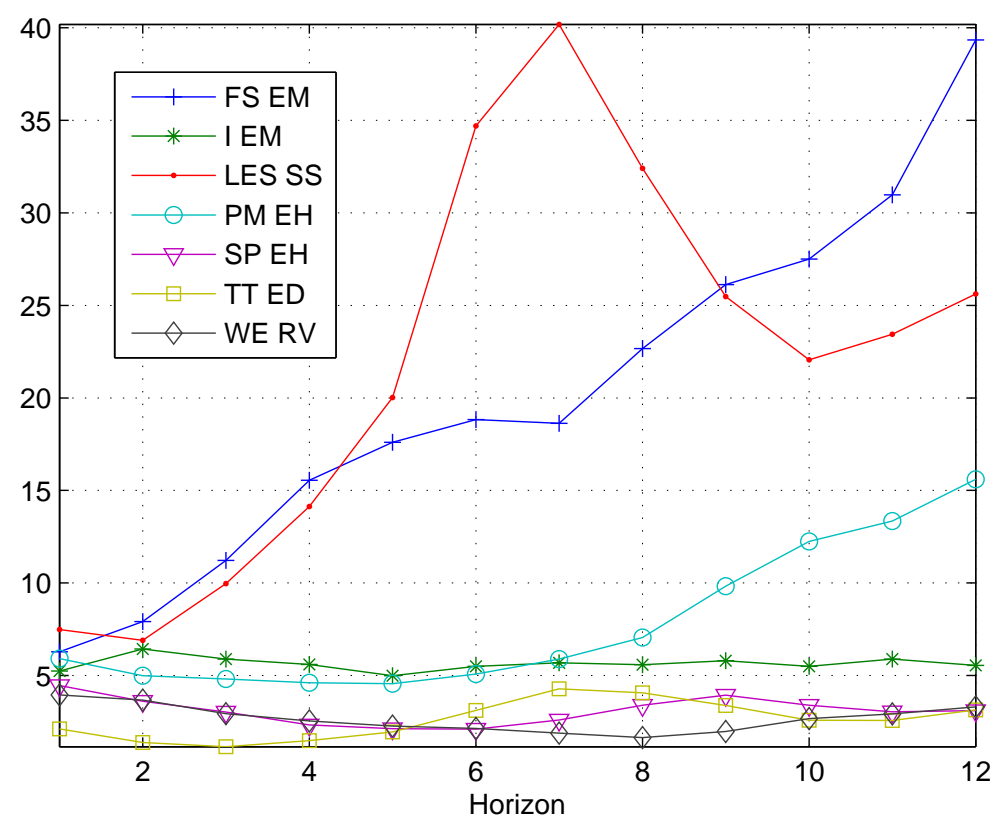

Figure 2: Term Structure of Fitted Sharpe Performances 